\title{
Composites of Heavy Rain Producing Elevated Thunderstorms in the Central United States
}

\author{
Laurel P. McCoy, ${ }^{1}$ Patrick S. Market, ${ }^{1}$ Chad M. Gravelle, ${ }^{2}$ Charles E. Graves, ${ }^{3}$ Neil I. Fox, \\ Scott M. Rochette, ${ }^{4}$ Joshua Kastman, ${ }^{1}$ and Bohumil Svoma ${ }^{1}$ \\ ${ }^{1}$ Department of Soil, Environmental and Atmospheric Sciences, University of Missouri, 302 ABNR, Columbia, MO 65211, USA \\ ${ }^{2}$ NWS Operations Proving Ground, CIMSS/SSEC, University of Wisconsin-Madison, NOAA/NWS Training Center, \\ 7220 N.W.101st Terr, Kansas City, MO 64153, USA \\ ${ }^{3}$ Department of Earth \& Atmospheric Sciences, Saint Louis University, O’Neil Hall, Room 205A, 3642 Lindell Blvd, Saint Louis, \\ MO 63108, USA \\ ${ }^{4}$ The College at Brockport, State University of New York, 350 New Campus Drive, Brockport, NY 14420-2936, USA
}

Correspondence should be addressed to Patrick S. Market; marketp@missouri.edu

Received 23 December 2016; Revised 9 March 2017; Accepted 19 March 2017; Published 20 June 2017

Academic Editor: Zheng Duan

Copyright (c) 2017 Laurel P. McCoy et al. This is an open access article distributed under the Creative Commons Attribution License, which permits unrestricted use, distribution, and reproduction in any medium, provided the original work is properly cited.

Composite analyses of the atmosphere over the central United States during elevated thunderstorms producing heavy rainfall are presented. Composites were created for five National Weather Service County Warning Areas (CWAs) in the region. Events studied occurred during the warm season (April-September) during 1979-2012. These CWAs encompass the region determined previously to experience the greatest frequency of elevated thunderstorms in the United States. Composited events produced rainfall of $>50 \mathrm{~mm} 24 \mathrm{hr}^{-1}$ within the selected CWA. Composites were generated for the $0-3 \mathrm{hr}$ period prior to the heaviest rainfall, 6-9 hours prior to it, and 12-15 hours prior to it. This paper focuses on the Pleasant Hill, Missouri (EAX) composites, as all CWA results were similar; also these analyses focus on the period 0-3 hours prior to event occurrence. These findings corroborate the findings of previous authors. What is offered here that is unique is (1) a measure of the interquartile range within the composite mean fields, allowing for discrimination between variable fields that provided a strong reliable signal, from those that may appear strong but possess large variability, and (2) composite soundings of two subclasses of elevated thunderstorms. Also, a null case (one that fits the composite but failed to produce significant rainfall) is also examined for comparison.

\section{Introduction}

Elevated thunderstorms, as studied by $[1,2]$, are thunderstorms that occur over a very stable surface boundary layer, essentially cut off from surface-based instability. In the United States, elevated thunderstorms are most common in the middle third of the country, having a climatological maximum located in eastern Kansas [1]. Reference [1] used three criteria to discriminate elevated thunderstorm station reports from surface-based thunderstorm station reports: (1) the observation must lie on the cold side of an analyzed front that shows a clear contrast in temperature, dew point temperature, and wind; (2) the station's wind, temperature, and dew point temperature must be qualitatively similar to the immediately surrounding values; and (3) the surface air on the warm side of the analyzed front must have a higher equivalent potential temperature $\left(\theta_{e}\right)$ than the air on the cold side of the front. These three criteria have been incorporated into several studies and climatologies to evaluate elevated thunderstorms (e.g., [3-7]).

Yet, elevated convection can take a variety of forms and can be very similar to surface-based convection. Reference [8] describes the challenge of finding the originating layer of parcels making up a convective cloud. Surface-based convection often incorporates elevated parcels; likewise elevated convection can bring surface parcels into its updraft. The distinction between surface-based and elevated convection can be highlighted by the height at which parcels originate. This 
difference becomes especially hard to make as convection transitions from surface-based to elevated convection and vice-versa [8].

The two most common severe weather threats associated with elevated thunderstorms are heavy rainfall leading to flash flooding and hail $[3,8-10]$. This study focuses on elevated thunderstorms that produce heavy rainfall in the geographic region encompassing the elevated thunderstorm occurrence maximum found by [1], but with a relaxed set of selection criteria as alluded to by [8]. As such, a more holistic view of elevated convection is employed, one which still requires the basic ingredients (moisture, lift, and instability) for deep moist convection [11]. Yet, this view foregoes the rigid need for a significant frontal boundary/inversion [1, $7,12,13]$ and the possibility for surface-based parcels to be incorporated into the layer above an inversion [8], even though the latter influences the vertical wind profile (which can lead to "training echoes" (e.g., [14])) as well as the inflow layer [15]. Indeed, there is mounting evidence that a spectrum of convective types exists between purely surface-based and purely elevated convection (e.g., $[16,17])$. Therefore, the goals of this study are to (1) compare current composites to previous findings regarding synoptic and mesoscale environmental conditions that lead to the development of heavy rain producing elevated thunderstorms, and (2) differentiate elevated thunderstorms that produce heavy rainfall from those that produce significantly less rainfall in similar synoptic settings.

To accomplish these ends, this paper will take the following form. In Section 2, we will detail the data employed in this study and our analysis methods. Section 3 details our composite analyses. Section 4 offers a null case, which appears to conform to the composites, yet fails to produce widespread, significant rainfall. Section 5 offers concluding remarks.

\section{Data and Methods}

To analyze the environment of the heavy rain producing elevated thunderstorms, events were collected within five National Weather Service (NWS) County Warning Areas (CWA; Figure 1): Pleasant Hill, Missouri (EAX); Springfield, Missouri (SGF); Tulsa, Oklahoma (TSA); Wichita, Kansas (ICT); and Topeka, Kansas (TOP). Because the individual CWAs had quite similar results, we focus on EAX for the bulk of the paper.

2.1. Event Selection. Heavy rain producing thunderstorm events, those having precipitation greater than $50.8 \mathrm{~mm}$ $24 \mathrm{hr}^{-1}$ within one of the aforementioned CWAs, were chosen after analyzing daily (i.e., $24 \mathrm{~h}$ period from 1200 to 1200 UTC) precipitation from the US Unified Daily Precipitation Analyses (http://www.esrl.noaa.gov/psd/data/gridded/data .unified.daily.conus.html) for the months April through September between 1979 and 2012. In order for any one of these events to be considered elevated, one of the following conditions had to be met:

(1) The precipitation occurred on the cool side of a clearly defined $2 \mathrm{~m} \theta_{e}$ gradient (as in [1]; detailed above), or

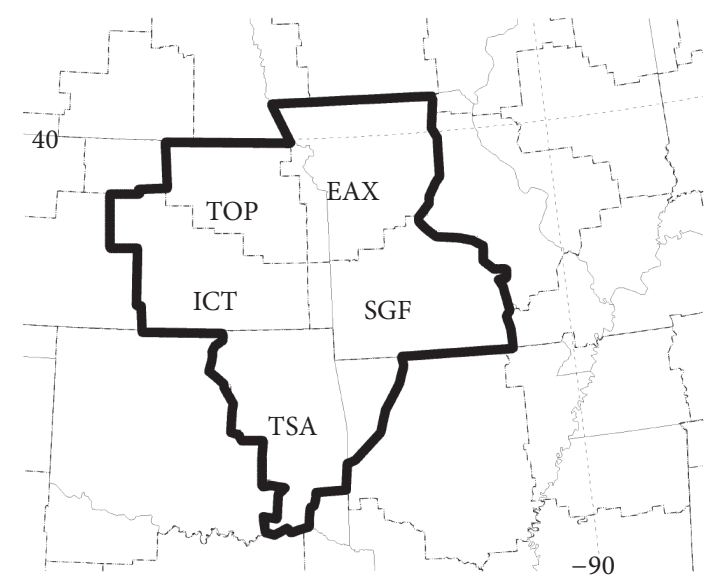

FIGURE 1: Map of the central United States, showing basic political outlines, and the selected National Weather Service County Warning Areas for this study. Compare to [1] and his Figure 1.

(2) there was a low-level inversion in both the vertical $\theta_{e}$ profile and the reanalysis sounding (more in keeping with the continuum concept of [8] for the location of maximum precipitation, immediately prior to precipitation onset.

These methods will be described further below.

In this study, $50 \mathrm{~mm}(\sim 2 \mathrm{in}$.) of precipitation within a $24 \mathrm{~h}$ period was chosen because the $100 \mathrm{~mm}$ ( $\sim 4$ in.) criteria in [7] failed to generate enough events in any of the five CWAs for the results to potentially be statistically significant. However, this threshold included many flash flood events (70\%, between 1996 and 2010 according to the online Storm Events Database (http://www.ncdc.noaa.gov/stormevents/)) and provides a unique study sample that exceeds [7] in quantity and $[1,2]$ in temporal coverage.

North America Regional Reanalysis (NARR) grid files were then used to provide long-term, coherent meteorological details on each event in the 34-year period. The NARR is a $32 \mathrm{~km}$, dynamically consistent atmospheric and surface hydrology dataset created by assimilating observations from multiple sources [18]. The dataset covers the period from 1 January 1979 to the present, with eight grids created for every day covering three-hour time periods. The start time for each event was defined as the time immediately prior to the NARR $3 \mathrm{~h}$ accumulated precipitation maximum.

Once the time for each event was found, the NARR $2 \mathrm{~m}$ $\theta_{e}$ and $3 \mathrm{~h}$ accumulated precipitation were used to determine if the precipitation maximum resulted from elevated convection (i.e., on the cold side of a surface boundary or above a low-level inversion). This was further corroborated by a subjective analysis of the surface $\theta_{e}$ for each event. If an identifiable surface boundary south of the precipitation maximum was not found [1], a point sounding was created using the NARR dataset to determine if an inversion (e.g., $[8,15]$ of at least $25 \mathrm{hPa}$ in depth (an arbitrary but typical value), at or above the surface, was present for the event to be considered elevated. Events were thus sorted into (1) frontal 
or (2) nonfrontal, for both climatological and sounding analysis.

Analysis is also shown for the EAX CWA to look at the distribution of events by month through the warm season. To do this the events which occurred for each month from April through September were counted. This method was repeated to show the favorable time of day for events to occur. Simple spreadsheet manipulation tallied the number of events that occurred at the eight, three-hour synoptic times between 0000 UTC and 2100 UTC. This process was performed for the two classes of elevated convection defined above: both frontal events and those with only an inversion.

2.2. Creating Composites. This methodology yielded a database of heavy rain producing elevated thunderstorm events for each CWA that included the date, time, and location for each event. The complete list of the events used in the EAX composites can be found in Table 1 . These events were used to generate CWA-centric, systemrelative composites for the heavy rain producing elevated thunderstorms 12-15 hours before, 6-9 hours before, and 0-3 hours before the event time using software developed at Saint Louis University (e.g., [7, 19]). For each elevated thunderstorm event, a 207-by-207 grid $(32 \mathrm{~km}$ by $32 \mathrm{~km}$ grid spacing) was extracted from the NARR dataset that was centered on the precipitation maximum, and these grids were used to create the system-relative composites for each CWA. Once the composites were generated, the results for each CWA were geographically centered on the CWA polygon for display purposes.

We note that the NARR fields were employed to generate these composite fields, and $\sim 61 \%$ of the events ( 20 of the 33 post-1995 events for which adequate radar data existed) examined had convection ongoing at the event time. In spite of this potential "convective contamination," the composites leading up to the event time (not shown) were trending in the direction of the signatures shown here. Moreover, these patterns and trends have been observed by the authors numerous times in operational numerical model output.

It is also acknowledged that the composite analysis approach has inherent limitations that may lead to misinterpretation of the results. Most notably, when averaging numerous events together important details in each event can be lost as the initial Barnes analysis and composite averaging can reduce the magnitude and alter the location of features [7]. Therefore, it is important to analyze the individual events in the database to determine if the composite results are representative of the case. In order to analyze the representativeness of the composite results, selected spaghetti plots were created and examined. However, this subjective analysis was formalized by computing interquartile ranges, which were generated by subtracting the 25 th percentile parameters from the 75th percentile parameters. This method highlights the magnitude and spatial variability in each parameter relative to the averages.

Finally, composite soundings were created for the location where the heaviest rainfall began, for the time 0-3 hours prior to the start of that rainfall, using the approach developed by [20] and employed by others (e.g., [21]). With
TABLE 1: Cases used within the EAX CWA to create composites, including the event date, composited NARR time (UTC), and local precipitation maximum coordinate (Lat/Lon). Dates in italics are the nonfrontal dates; dates without italics are the frontal cases.

\begin{tabular}{|c|c|c|}
\hline Date & Time & Lat/Lon \\
\hline $05 / 18 / 81$ & 06 & $39.35 ;-93.02$ \\
\hline $06 / 15 / 81$ & 09 & $38.39 ;-93.96$ \\
\hline $07 / 23 / 81$ & 06 & $39.46 ;-92.67$ \\
\hline $07 / 25 / 81$ & 09 & $39.49 ;-92.96$ \\
\hline $07 / 26 / 81$ & 12 & $39.29 ;-94.26$ \\
\hline 08/13/82 & 09 & $38.32 ;-94.24$ \\
\hline $08 / 26 / 82$ & 12 & $39.92 ;-93.85$ \\
\hline $04 / 01 / 83$ & 09 & $38.95 ;-94.51$ \\
\hline $05 / 01 / 83$ & 06 & $38.78 ;-92.84$ \\
\hline $07 / 04 / 84$ & 09 & $39.26 ;-94.14$ \\
\hline 09/14/84 & 09 & $38.89 ;-93.53$ \\
\hline $06 / 03 / 85$ & 21 & $38.45 ;-94.76$ \\
\hline 09/21/85 & 00 & $39.86 ;-94.14$ \\
\hline $07 / 11 / 86$ & 09 & $38.26 ;-94.72$ \\
\hline 09/11/86 & 03 & $39.61 ;-95.17$ \\
\hline $09 / 23 / 86$ & 12 & $39.36 ;-92.65$ \\
\hline 07/07/87 & 12 & $40.00 ;-93.67$ \\
\hline $07 / 12 / 87$ & 09 & $40.07 ;-93.31$ \\
\hline 09/16/88 & 09 & $39.70 ;-93.31$ \\
\hline 08/21/89 & 06 & $38.29 ;-93.61$ \\
\hline 08/28/89 & 12 & $40.33 ;-94.23$ \\
\hline 05/15/90 & 12 & $38.91 ;-92.81$ \\
\hline $07 / 11 / 91$ & 03 & $40.28 ;-93.51$ \\
\hline 07/23/93 & 12 & $40.42 ;-95.48$ \\
\hline 09/22/93 & 09 & $39.71 ;-93.94$ \\
\hline $04 / 28 / 94$ & 06 & $38.37 ;-94.71$ \\
\hline 05/16/95 & 12 & $38.71 ;-93.23$ \\
\hline $05 / 23 / 95$ & 12 & $39.71 ;-94.37$ \\
\hline 07/04/95 & 09 & $40.39 ;-93.99$ \\
\hline 07/20/95 & 09 & $39.00 ;-94.92$ \\
\hline $05 / 27 / 96$ & 06 & $39.81 ;-92.79$ \\
\hline 07/21/96 & 03 & $38.85 ;-93.47$ \\
\hline 08/19/97 & 09 & $38.17 ;-94.66$ \\
\hline 07/30/98 & 09 & $39.18 ;-94.84$ \\
\hline 09/13/98 & 12 & $38.86 ;-93.96$ \\
\hline 09/28/99 & 06 & $39.90 ;-92.89$ \\
\hline $06 / 24 / 00$ & 06 & $40.10 ;-94.67$ \\
\hline 08/20/00 & 03 & $39.98 ;-94.80$ \\
\hline 06/03/01 & 12 & $38.79 ;-94.94$ \\
\hline 06/06/01 & 03 & $38.99 ;-93.77$ \\
\hline 07/12/01 & 06 & $39.37 ;-94.39$ \\
\hline $07 / 25 / 01$ & 06 & $39.68 ;-93.31$ \\
\hline 09/17/01 & 03 & $39.49 ;-94.49$ \\
\hline 05/12/02 & 03 & $40.06 ;-92.69$ \\
\hline 05/18/04 & 12 & $38.98 ;-94.63$ \\
\hline 07/16/04 & 09 & $39.14 ;-94.50$ \\
\hline $07 / 24 / 04$ & 12 & $38.77 ;-95.00$ \\
\hline
\end{tabular}


TABLE 1: Continued.

\begin{tabular}{lcc}
\hline Date & Time & Lat/Lon \\
\hline $08 / 04 / 04$ & 09 & $38.94 ;-92.77$ \\
$07 / 18 / 05$ & 06 & $40.15 ;-95.31$ \\
$05 / 06 / 07$ & 12 & $39.81 ;-93.84$ \\
$08 / 24 / 07$ & 06 & $39.74 ;-94.79$ \\
$07 / 25 / 08$ & 06 & $40.19 ;-92.78$ \\
$07 / 28 / 08$ & 09 & $40.46 ;-93.67$ \\
$09 / 12 / 08$ & 12 & $38.94 ;-94.32$ \\
$05 / 10 / 10$ & 15 & $39.27 ;-94.19$ \\
$06 / 08 / 10$ & 12 & $40.19 ;-93.14$ \\
$06 / 14 / 10$ & 06 & $40.17 ;-93.64$ \\
$07 / 20 / 10$ & 06 & $40.48 ;-92.58$ \\
$09 / 11 / 10$ & 03 & $38.78 ;-93.03$ \\
$09 / 15 / 10$ & 12 & $38.32 ;-94.95$ \\
\hline
\end{tabular}

this approach, the top and bottom of the inversion, both (1) associated with a frontal zone (following [1]) and (2) from other nonfrontal origins (following [8]), were the features that we sought to preserve.

\section{Composite Analyses}

3.1. Monthly and Diurnal Patterns. The monthly frequency of the heavy rain producing elevated thunderstorm events in the EAX CWA is shown by the total monthly tallies in Figure 2. In contrast with the results in the 1979-1982 study in [1], many of the 60 events in this database, both of the $[1,8]$ variety, occurred during the month of July (23) and the least occurred in April (2 events). However, the [1] study counted each synoptic report of elevated convection. The present study evaluates only episodes of elevated convection with heavy rainfall and treats every such episode as a single event, linked to its start time (discussed in the previous section), though there may have been multiple synoptic reports in each episode. Not surprisingly, a diurnal signal is present in the database (Figure 3), as most of the events occurred between 0600 UTC and 1200 UTC, with nonfrontal events maximized at 0600 UTC and frontal events at 1200 UTC. Furthermore, $90 \%$ of the events occurred between 0300 and 1200 UTC. Although [1] could not conclusively determine the validity of a diurnal tendency in his database, these results clearly show there is a clear diurnal (overnight) preference for heavy rain producing elevated thunderstorms (of both kinds) in the central United States, due likely to the activation of the lowlevel jet above a stable boundary layer (e.g., [12]), which we corroborate with the cross-section analyses herein.

3.2. Environmental Analysis. The system-relative composites generated for the five NWS CWAs showed quite similar elevated thunderstorm environments. Therefore, the composite results from the (EAX) CWA will be used to represent the environmental analysis seen with heavy rain producing elevated thunderstorms in this region.

3.2.1. Upper-Air Analysis. For the composite event, the region of heavy precipitation is just upstream of a $250 \mathrm{hPa}$ ridge,

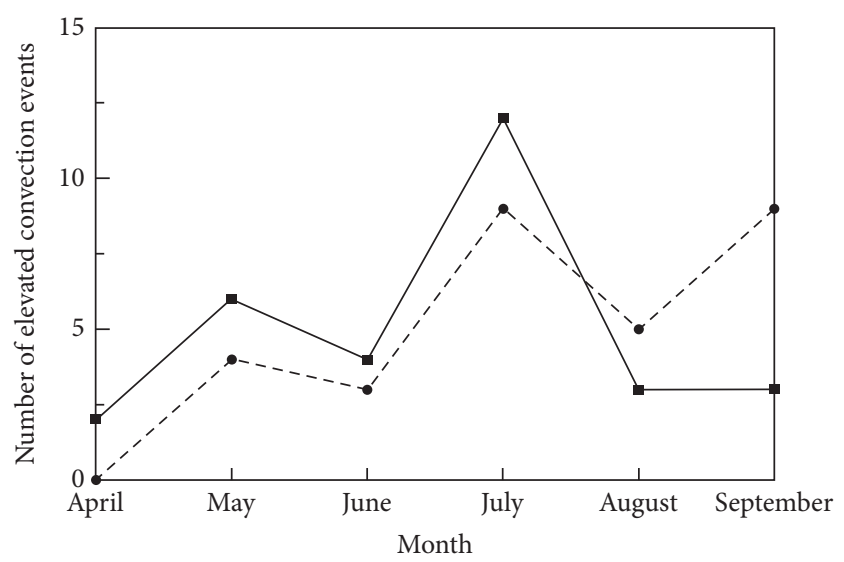

FIGURE 2: Number of elevated convection events with heavy rainfall, by month, in the EAX CWA for frontal (dashed line) and nonfrontal (solid line) case collections for the period 1979-2012.

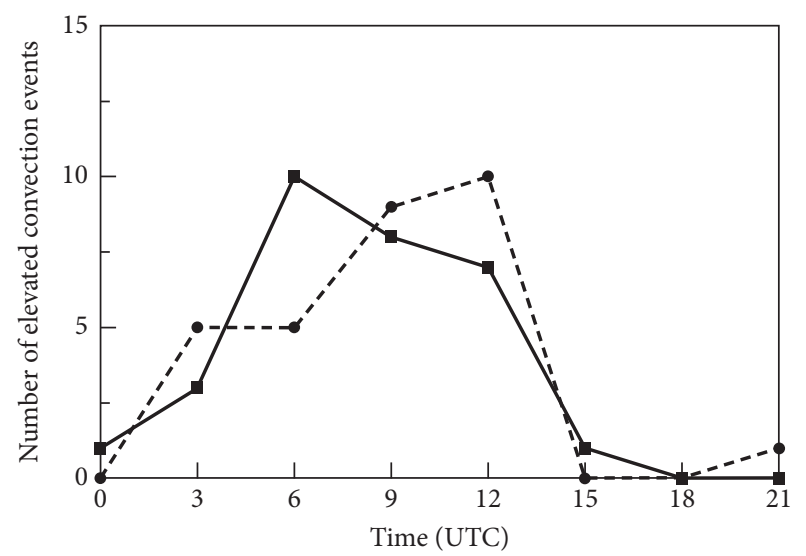

FIGURE 3: Number of elevated convection events with heavy rainfall, by hour, in the EAX CWA for frontal (dashed line) and nonfrontal (solid line) case collections for the period 1979-2012.

with a trough over the Rocky Mountains and a second weaker trough over the northeastern US (Figure 4(a)). The plot for the interquartile range (IQR) for geopotential height (Figure 4(b)) shows little discrepancy over the location of the upper-level features, but there is some spread in the magnitude of the ridge and troughs.

While the trough at $250 \mathrm{hPa}$ propagates eastward over the 12 hours leading up to the event (not shown), the jet streak in all five CWAs tends to build backward, appearing to strengthen or propagate westward. While the IQR plots show some incongruity between events in the location and magnitude of the jet streak to the northwest (Figure 4(c)), lesser spread $\left(<30 \mathrm{kts}\right.$, or $\left.<15 \mathrm{~ms}^{-1}\right)$ is located over the entrance region of the jet streak to the northeast. This intensification could be in response to the convection developing over the region. Strong divergence and diffluence near the uppertroposphere in the storm region can be attributed to the significant upward transport of mass and latent heat released during condensation. The divergence and diffluence create a 


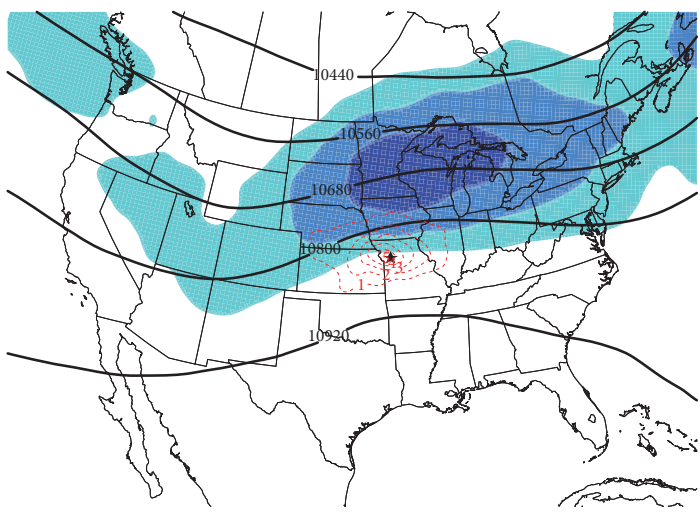

$$
\begin{array}{ccccc}
50 & 60 & 70 & 80 & 90 \\
\hline \text { Elevated heavy rain composite } & 250-\mathrm{hPa} \text { heights [gpm; solid], }
\end{array}
$$

isotachs [kts, shaded], and divergence $\left[\times 10^{-5} \mathrm{~s}^{-1}\right.$, dashed] at $t=00$

(a)

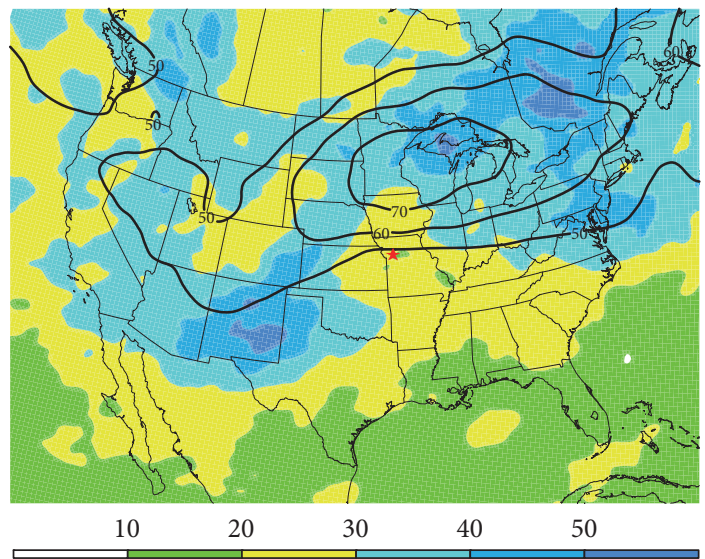

Mean 250-hPa wind speed [kts; solid], $75-25$ percentile spread [kts; shaded]

(c)

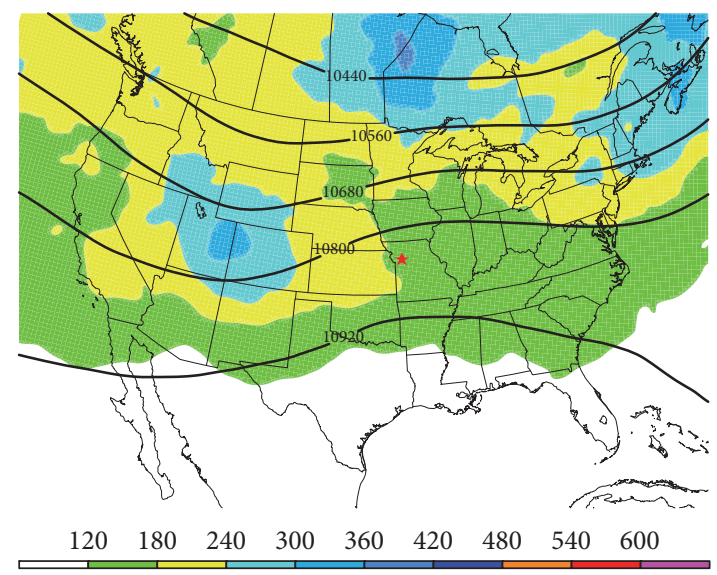

Mean 250-hPa Geopo. Hght [gpm; solid], 75-25 percentile spread [gpm; shaded]

(b)

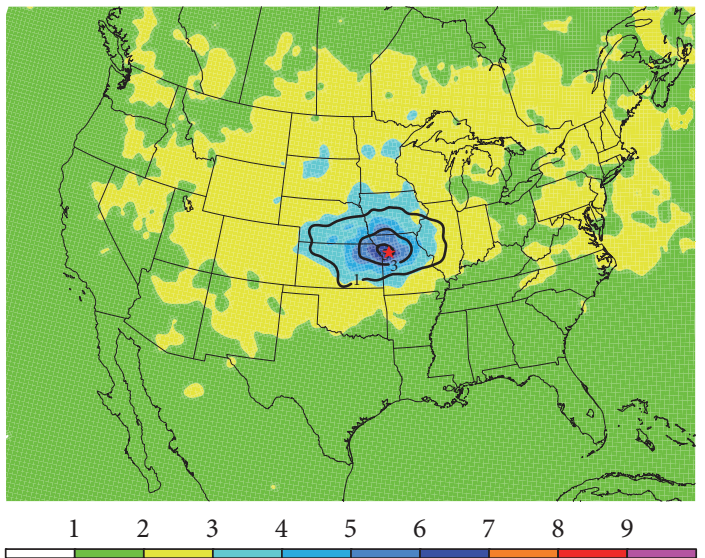

(d)

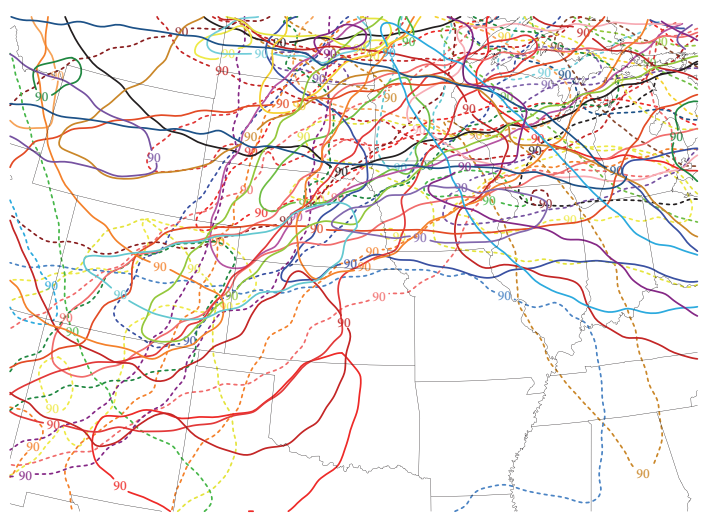

90-knot isotach at 250-mb for each component case

(e)

FIGURE 4: EAX CWA composite for 0-3 hr prior to event time showing $250 \mathrm{hPa}$ : (a) geopotential height (black, gpm), isotachs (color-filled, $\mathrm{kts}$ ), and divergence (dashed, $\times 10^{-5} \mathrm{~s}^{-1}$ ); (b) mean geopotential height (black, gpm) and 75-25 percentile mean spread (color-filled, gpm); (c) mean wind speed (black, kts) and 75-25 percentile mean spread (color-filled, kts); (d) mean divergence (black, $\times 10^{-5} \mathrm{~s}^{-1}$ ) and $75-25$ percentile mean spread (color-filled, $\times 10^{-5} \mathrm{~s}^{-1}$ ); (e) regional spaghetti plot of the 90 -knot isotach at $250 \mathrm{hPa}$ from each composite member (each is a different color). The star is located at the centroid of the CWA. 


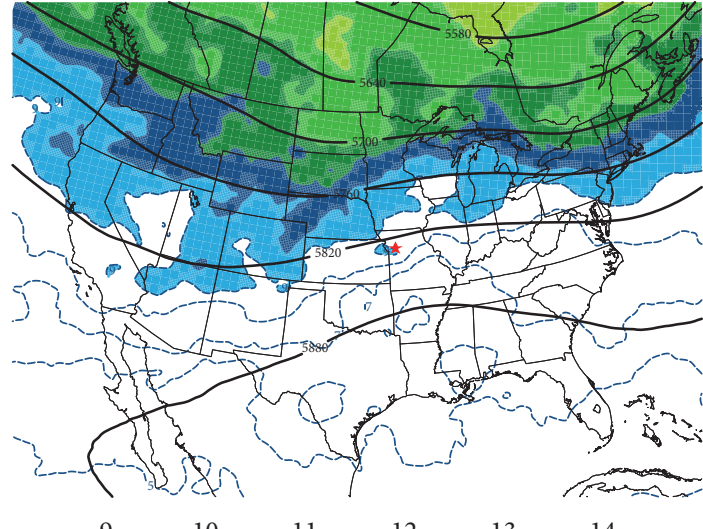

14

Elevated heavy rain composite 500-hPa geopotential heights [gpm, solid] Absolute vorticity $\left[\times 10^{-5} \mathrm{~s}^{-1}\right.$; dashed, shaded $\left.>9\right]$ at $t=00$

(a)

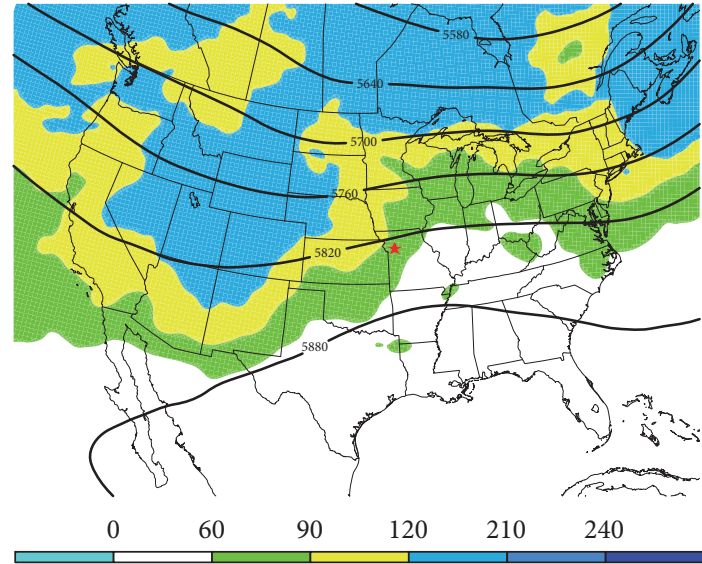

Mean 500-hPa Geopo. Hght [gpm; solid], 75-25 percentile spread [gpm; shaded]

(b)

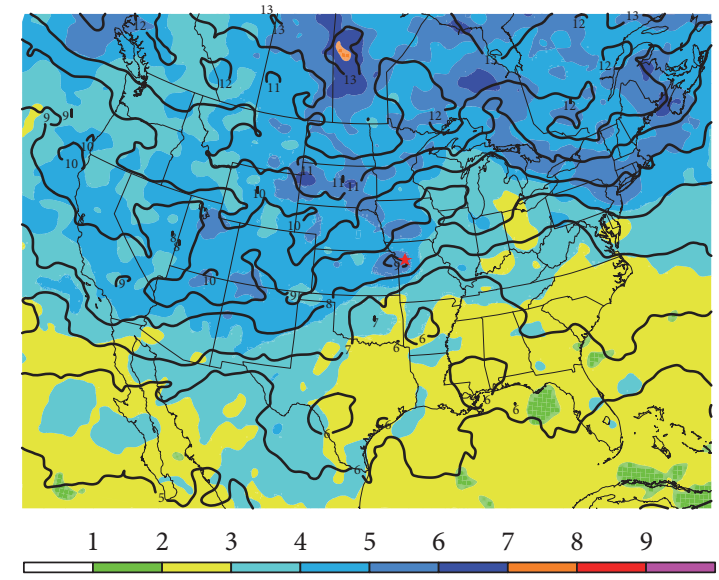

Mean 500-hPa abs. vort. $\left[\times 10^{-5} \mathrm{~s}^{-1}\right.$; solid $]$, 75-25 percentile spread [shaded]

(c)

FIGURE 5: EAX CWA composite for 0-3 hr prior to event time showing $500 \mathrm{hPa}$ (a) geopotential height (black, gpm) and absolute vorticity (dashed, color-filled $>9 \times 10^{-5} \mathrm{~s}^{-1}$ ); (b) mean geopotential height (black, gpm) and 75-25 percentile mean spread (color-filled, gpm); (c) mean absolute vorticity (black, $\times 10^{-5} \mathrm{~s}^{-1}$ ) and 75-25 percentile mean spread (color-filled, $\times 10^{-5} \mathrm{~s}^{-1}$ ). The star is located at the centroid of the CWA.

new jet streak with the storm area located in its right entrance region (e.g., [22]).

A weak maximum in divergence is located over the event location 12 hours prior to the event; this maximum remains fairly weak over the next six hours, as the jet streak to the northeast strengthens westward (not shown). Mean and spread plots for the event time show that weak divergence at $250 \mathrm{hPa}$ is common 12 and even 6 hours before the event time, with little spread $\left(<4 \times 10^{-5} \mathrm{~s}^{-1}\right)$ over the region, likely highlighting disagreements in location more than magnitude. By the time of the event (Figure 4(a)), divergence has increased dramatically over the event location. The IQR shows spread (Figure 4(d)) among the composited events in the location of the divergence maximum over the site where heavy rainfall occurs. The large spread is due in part to the location of the of the parent jet maximum, a sample of which is shown in Figure 4(e) using the 90-knot isotach from each event; it also reveals a clear preference for events to occur on the equatorward side of the upper-level jet maximum.

At $500 \mathrm{hPa}$, a weak ridge is situated over the region as identified in prior research (e.g., [5, 7]), with the event location just upstream of the ridge axis (Figure 5(a)). The IQR plot (Figure 5(b)) indicates that the location is fairly consistent between the cases within the composite, but the magnitude of the ridge and troughs on either side may differ. It is also evident from the mean that weak positive vorticity advection occurs just ahead of the event, as an increase of $1-3 \times 10^{-5} \mathrm{~s}^{-1}$ is seen in all the composites over the 6-hour period leading up to the event (Figure 5(c)). Though this may occur, the spread plots indicate a spread over the location of $>5 \times 10^{-5} \mathrm{~s}^{-1}$, meaning that the vorticity maximum is not a systematic feature of these events. 


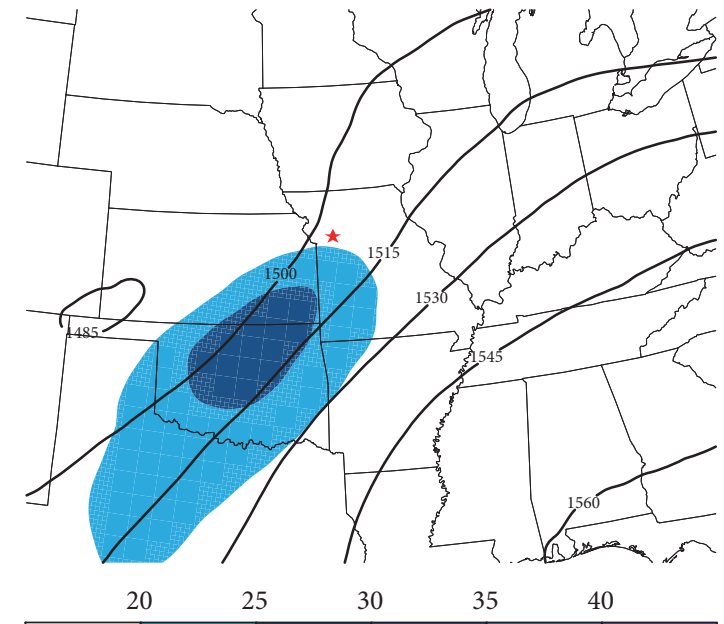

Elevated heavy rain composite 850 -hPa geopotential heights [gpm, solid], and isotachs [kts, shaded $>20]$ at $t=00$

(a)

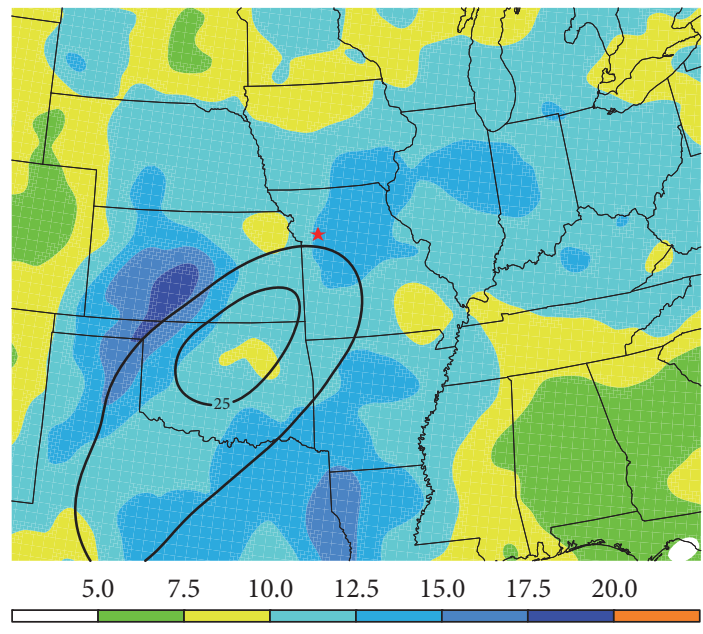

Mean 850-hPa wind speed [kts, contours] and 75-25

percentile spread [kts, shaded] at $t=00$

(c)

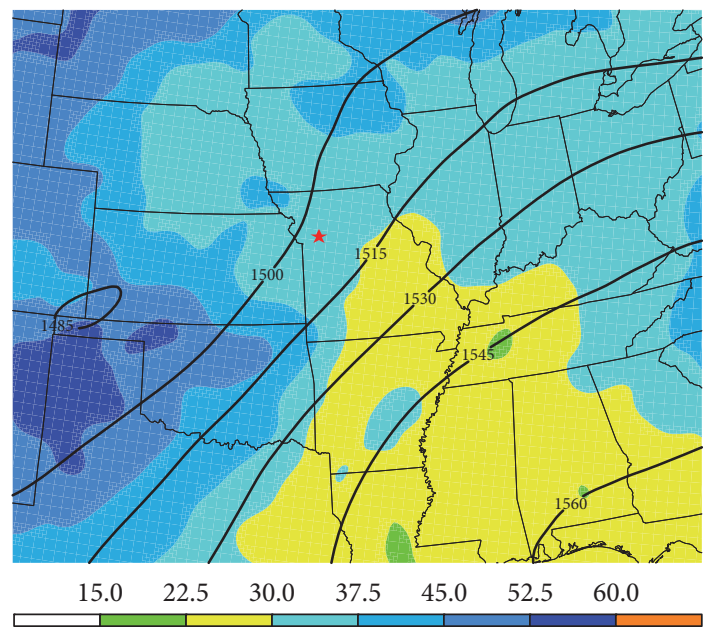

Mean 850-hPa geopotential height [gpm, contours] and 75-25 percentile spread [gpm, shaded] at $t=0$

(b)

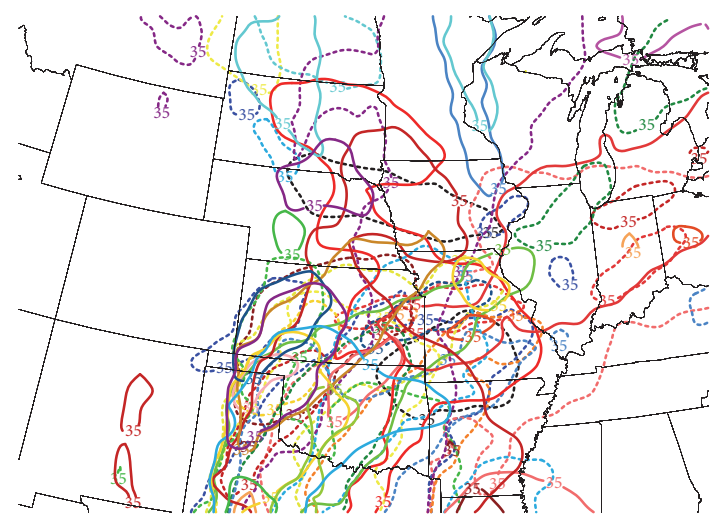

35-knot isotach at $850-\mathrm{mb}$ for each component case

(d)

FIGURE 6: EAX CWA composite for $0-3 \mathrm{hr}$ prior to event time showing $850 \mathrm{hPa}$ : (a) geopotential height (black, gpm) and isotachs $>20 \mathrm{kts}$ (color-filled); (b) mean geopotential height (black, gpm) and 75-25 percentile mean spread (color-filled, kts); (c) mean isotachs $>20$ kts (black) and 75-25 percentile mean spread (color-filled, kts); (d) regional spaghetti plot of the 35-knot isotach at $850 \mathrm{hPa}$ from each composite member (each is a different color). The star is located at the centroid of the CWA.

3.2.2. Low-Level Analysis. The composites at $850 \mathrm{hPa}$ reveal a height gradient over the event region, with lower geopotential heights to the northwest and greater heights to the southeast (Figure 6). The gradient strengthens from 12 to six hours earlier (not shown), generating a south-southwesterly lowlevel jet with mean winds increasing from $<20 \mathrm{kt}$ at 12 hours prior to exceeding $25 \mathrm{kt}$ at the event time (Figure 6(a)). The event is located in the left exit region of the low-level jet, consistent with the results found in $[1,7]$.

The $850 \mathrm{hPa}$ IQR plot (Figure 6(b)) suggests variability mainly over the location of the low-level jet, in the east and west directions. There appears to be a greater variability in magnitude of the low-level jet earlier before the event, but at the time of the event, the larger spread is found to the east and west of the feature (Figure 6(c)). This IQR result suggests significant variability, yet our experience supports the previous conclusion (e.g., $[1,7]$ ) that the best location for the development of heavy rain is in the left exit region of the low-level jet. The spaghetti plot of the 35-knot isotach at $850 \mathrm{mb}$ (Figure 6(d)) supports this view.

The formation of the low-level jet coincides with the $850 \mathrm{hPa} \theta_{e}$ advection maximum that appears at $850 \mathrm{hPa}$ (Figure $7(\mathrm{a})$ ), along the exit region of the low-level jet. The advection maximum is located over or just northeast of 


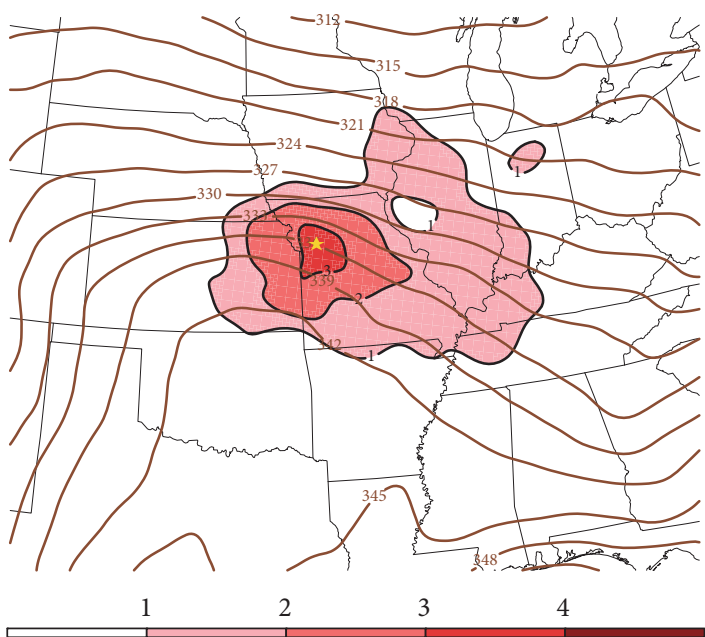

Elevated heavy rain comp $2 \mathrm{~m}$ Theta-E (K) and 850 -hPa Theta-E advection $\left(\mathrm{K} 3 \mathrm{hr}^{-1}\right)$

(a)

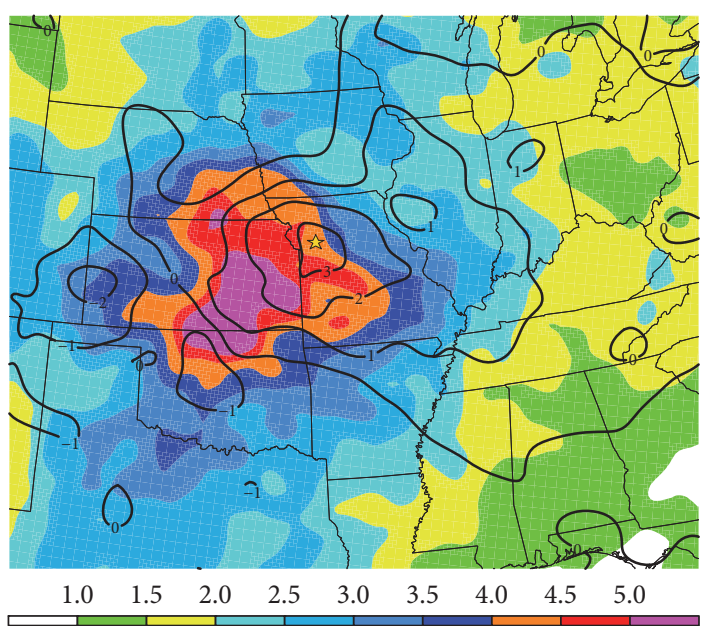

Composite $850-\mathrm{hPa}$ Theta-E advection [(K/3-hrs), contours] and $75-25$ percentile spread [(K/3-hrs), shaded $]$ at $t=0$

(b)

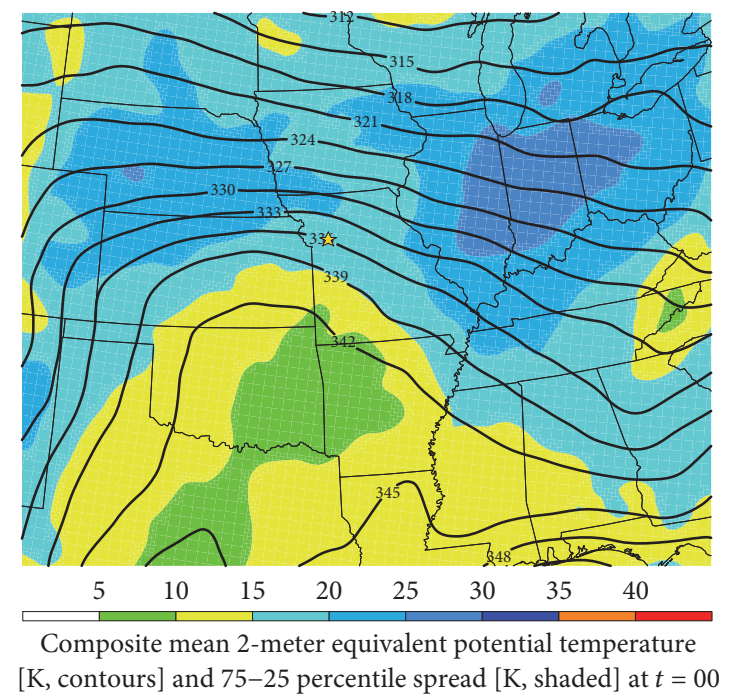

(c)

FigURE 7: EAX CWA composite for 0-3 hr prior to event time showing $850 \mathrm{hPa}$ : (a) equivalent potential temperature advection [color-filled, $\mathrm{K}\left(3 \mathrm{hr}^{-1}\right)$ ] and $2 \mathrm{~m}$ equivalent potential temperature (brown, $\left.\mathrm{K}\right)$; (b) mean $\theta e$ advection [black, $\mathrm{K}\left(3 \mathrm{hr}^{-1}\right)$ ] and $75-25$ percentile mean spread [color-filled, $\mathrm{K}\left(3 \mathrm{hr}^{-1}\right)$ ]; (c) mean $2 \mathrm{~m} \theta e$ (black, $\mathrm{K}$ ) and 75-25 percentile mean spread (color-filled, $\mathrm{K}$ ). The star is located at the centroid of the CWA.

the event location, to the north of the $2 \mathrm{~m} \theta_{e}$ boundary (Figure 7(a)). This maximum represents the location of mass convergence occurring along the northern extent of the low-level jet. This convergence region often represents the location of the southern extent of the low-level stable layer. The IQR plots (Figures 7(b) and 7(c)) show that although this feature exists, there is a large difference in both the magnitude and location of this $\theta_{e}$ advection maximum; therefore, this is clearly not a good parameter to use alone for finding the location of a heavy rainfall event. Yet, the IQR in the $2 \mathrm{~m} \theta_{e}$ boundary (Figure 7(c)) reveals the event to be on the cool side of the surface boundary, with values changing much more gradually in space.
3.2.3. Stability Analysis. Many different metrics were examined to assess the stability profile for each event. Of those, the most unstable convective available potential energy (MUCAPE) and the $K$ Index produced the most robust signals. The $K$ Index (e.g., [23]) performed particularly well in this analysis, likely because it considers only the environment above $850 \mathrm{hPa}$ and the calculation stays above the low-level stable layer most of the time. MUCAPE finds the most unstable parcel in the lowest $300 \mathrm{mb}$ and uses that to calculate the potential instability of the environment, and because several of these cases occurred either after a frontal passage or after dark, the surface-based parcel is found to be the most unstable 12 hours prior to the event. As a front approaches 


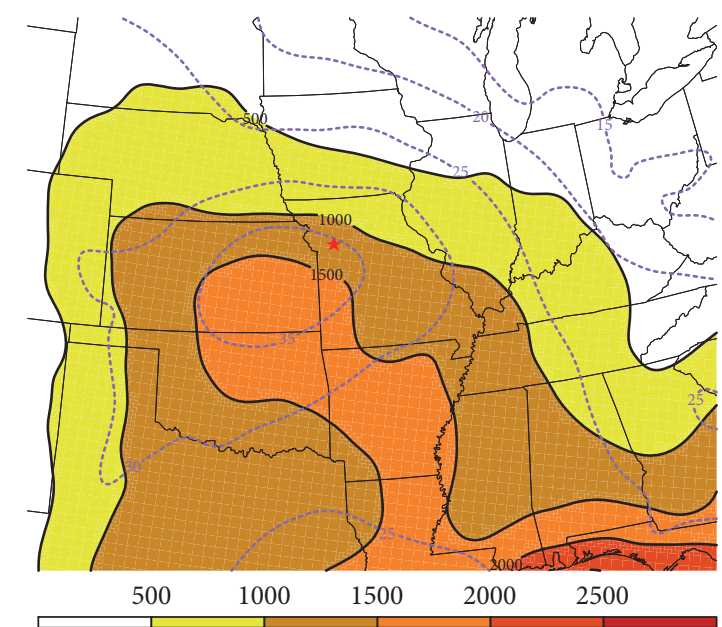

Elevated heavy rain composite most unstable CAPE [ $\mathrm{kg}^{-1}$, shaded] and $K$ index [purple, dashed] at $t=00$

(a)

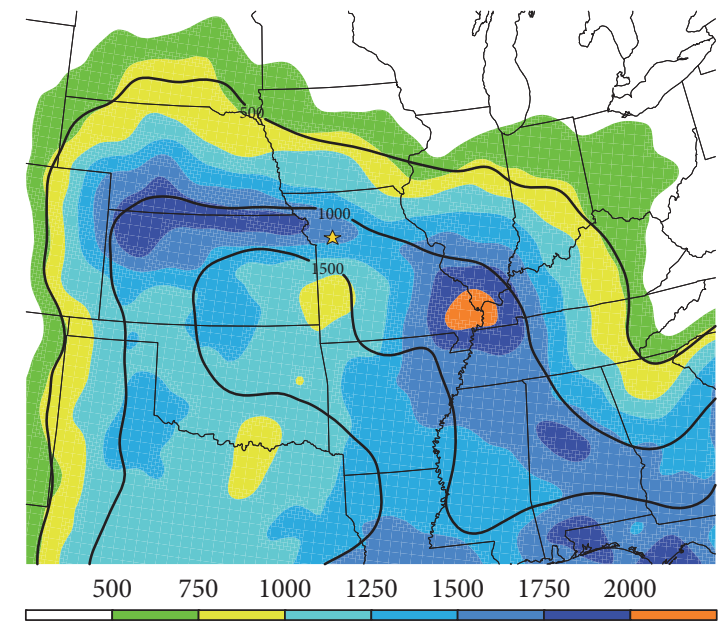

Composite mean most-unstable CAPE [J/kg, contours] and 75-25 percentile spread $[\mathrm{J} / \mathrm{kg}$, shaded] at $t=0$

(c)

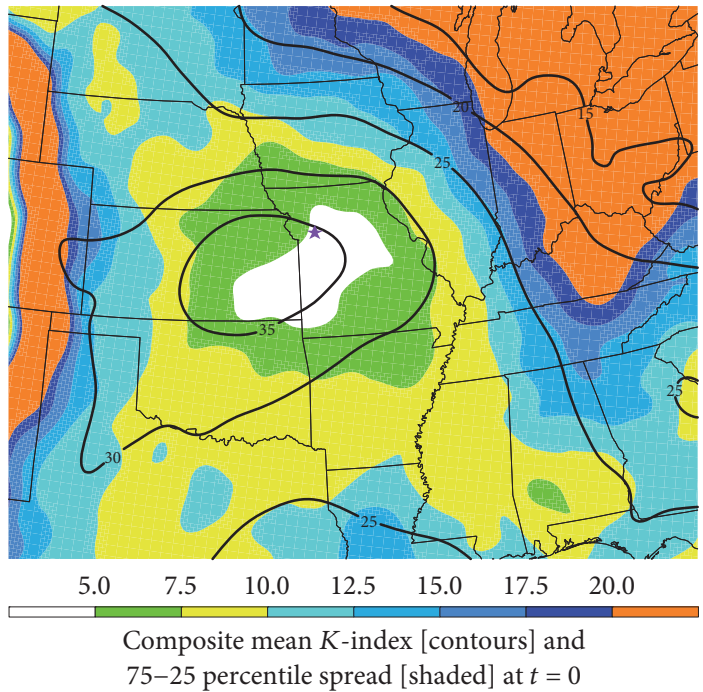

(b)

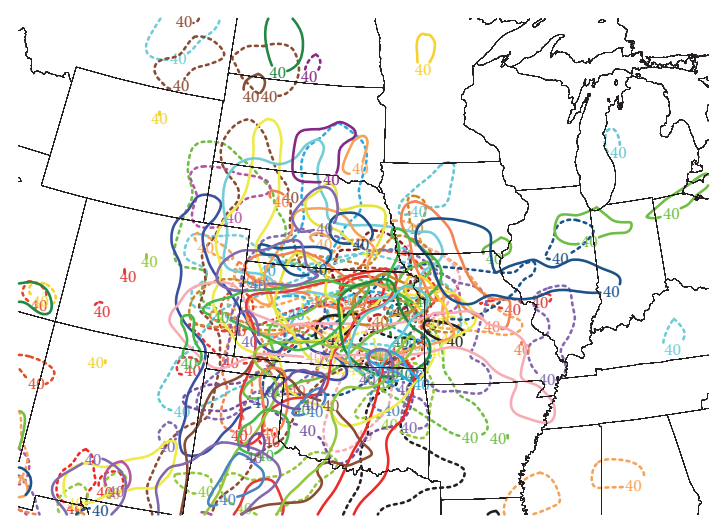

$K$ index 40 value contours for each component case

(d)

FIGURE 8: EAX CWA composite for 0-3 hr prior to event time showing (a) most unstable CAPE (color-filled, $\mathrm{J} \mathrm{kg}^{-1}$ ) and $\mathrm{K}_{\text {index }}$ (purple); (b) mean $K$ index (black) and 75-25 percentile mean spread (color-filled); (c) mean most unstable CAPE (black, J kg ${ }^{-1}$ ) and 75-25 percentile mean spread (color-filled, $\mathrm{J} \mathrm{kg}^{-1}$ ); (d) regional spaghetti plot of the $K$ Index $=40$ contour from each composite member (each is a different color). The star is located at the centroid of the CWA.

or the sun sets, the surface-based instability decreases, and MUCAPE begins to come from elevated parcels. This means that although the MUCAPE may continue decreasing during the 12-hour period leading up to the event (Figure 8(a)), the decrease should be less over the event location. Using the $K$ index, the elevated-unstable region stands out much more prominently than when using MUCAPE.

Although the composite MUCAPE reveals a fairly unstable environment, the $K$ index performs better at showing the increase in elevated instability with time. While MUCAPE values decrease over the region from 12 -hour prior toward the event time, $K$-index values increase from 30 to 35 (not shown). The 30 , and eventually 35 , contours appear to surge northward from the south-southwest, along the low-level jet, eventually placing the event location in the northeast part of the 35 contour.

The IQR plots show that the $K$ index (Figure $8(\mathrm{~b})$ ) is the better parameter to use for analyzing the increase in elevated instability. Twelve and six hours prior to the event (not shown) the region is covered by a MUCAPE spread of $>2000 \mathrm{~J} \mathrm{~kg}^{-1}$. During the same time periods, the $K$ index spread over the region is $<7.5$. While the spread in both decreases at the time of the event, the MUCAPE spread is still $>1500 \mathrm{~J} \mathrm{~kg}^{-1}$ over the event location (Figure $8(\mathrm{c})$ ). This is larger than the mean $\left(1000-1500 \mathrm{~J} \mathrm{~kg}^{-1}\right)$. The $K$ index spread at the event time reduces to $<5$. That is within one contour 
interval of the mean. Indeed the spaghetti plot of $K$ Index $=40$ (Figure $8(d)$ ) reveals clustering around and west of the EAX CWA.

3.2.4. Analysis of Heavy Rainfall Predictors. To analyze the amount of moisture in the thunderstorm environment, this study examines precipitable water values, in accordance with the method used by [7]. Reference [24] suggested looking at several other parameters, including the $1000-500 \mathrm{hPa}$ thickness for a diffluent pattern when forecasting a heavy rainfall event. The mean fields at the time of the event show a weak low pressure system just west of the event site, with precipitable water values $>45 \mathrm{~mm}(\sim 1.8 \mathrm{in}$.), and embedded in a region of 1000-500 hPa diffluent thickness (Figure 9(a)).

Sea level pressures show some variance in the IQR plots (Figure 9(b)), and these values are greater further poleward. Indeed, our day-to-day experience with such events has shown that neither a closed low nor a trough is required for the generation of heavy rainfall. Looking at $1000-500 \mathrm{hPa}$ layer thickness, all the composites show diffluent thickness patterns over the event region as early as 12 hours prior to the event (not shown), which appears to expand further downstream in the last six hours before the event. It is interesting to note that there appears to be little spread in the thickness field $(<4.5 \mathrm{dkm})$ over the event location from 12 hours up to the event time (Figure 9(c)). This indicates that the diffluent thickness pattern is common within a large number of the composited events. Lastly, moisture exists in abundance, even twelve hours prior to the event, with precipitable water values exceeding $35 \mathrm{~mm}$ ( $\sim 1.4$ in.; not shown). As the event time approaches, moisture is advected in by the low-level jet, increasing precipitable water values to over $41 \mathrm{~mm}(\sim 1.6$ in.) by the time of the event (Figure 9(a)); note that the EAX area was the outlier with values greater than $46 \mathrm{~mm}$ ( 1.8 in.). Even so, the IQR is minimized (12 mm or $\sim 0.4^{\prime \prime}$ ) at the event time (Figure $9(\mathrm{~d})$ ). The spaghetti plot of $50 \mathrm{~mm}$ of precipitable water (Figure 9(e)) again reveals clustering around the EAX CWA.

3.2.5. Cross-Section Analysis. A cross-section through the heavy rainfall event region 12 hours prior to the event (Figure 10(a)) shows an established direct thermal circulation, created by the entrance region of the upper-level jet streak. A potentially unstable layer is present over the event location, as seen by the decrease in $\theta_{e}$ with height up to $700 \mathrm{hPa}$. This pattern persists six hours prior to the event (Figure 10(b)), and the enhanced low-level flow (shown by the $15 \mathrm{kt}$ isotach) has developed toward the south and the surface. Finally, at the event time (Figure 10(c)), the ageostrophic circulation vectors show well the interaction of the lower-level flow and upperlevel jet, although one could argue that some of the composite members had already been contaminated by convection, even in the NARR assimilation process. Indeed, the significant upward (downward) surge of the $333 \mathrm{~K}$ contour near the surface (aloft) near the center of the plot (Figure 10(c)) suggests significant latent heat release.

Even so, the low-level flow also drives the warmer air above the shallow stable boundary layer (Figure 10(c)) upslope until it becomes incorporated into the direct thermal circulation created by the entrance region of the upper-level jet streak. Equivalent potential temperature on the crosssections shows the background potential instability where $\theta_{e}$ decreases with height over the event region (Figure 10); in all of the composite cross-sections this is found to occur between 850 and $700 \mathrm{hPa}$. Mixing ratio plotted on the crosssections shows moisture ascending in the column of vertical motion as well, with values of $3 \mathrm{~g} \mathrm{~kg}^{-1}$ ascending to $500 \mathrm{hPa}$ (Figure 10(c)). Meanwhile, the 65-knot plane-normal isotach steadily expands throughout the 12-hour period.

3.2.6. Sounding Analysis. In an effort to distinguish between frontal and nonfrontal elevated convection cases, composite soundings were also created for each class of event; these results are detailed in Figure 11. In the case of the frontal composites (Figure 11(a)), a clear frontal inversion existed in almost every one, so an inversion top and bottom were actively sought, averaged, and included in the plot. This was done in the nonfrontal case collection too (Figure 11(b)), with interesting differences from the frontal collection. Standard deviation "channels" are also included to highlight variability in the frontal (Figure 11(a)) versus the nonfrontal (Figure 11(b)) composites.

One feature that we note immediately is that the mean atmosphere is cooler in the frontal composite (Figure 11(a)) than in the nonfrontal composite (Figure 11(b)). Indeed the temperature at the surface level is one standard deviation cooler in the frontal than the nonfrontal composite. With regard to moisture, the frontal composite (Figure 11(a)) has lower dew point temperatures in the layer below $825 \mathrm{mb}$ than the nonfrontal composites (Figure 11(b)). Yet, the lowest $\sim 50 \mathrm{mb}$ possess notably smaller dew point depressions in the frontal cases; the same is true between 850 and $450 \mathrm{mb}$.

The resulting stability differences (based on the most unstable parcel) represented by these profiles are significant. The frontal composite (Figure 11(a)) reveals a much higher most unstable lifting parcel level, well above the mean inversion top, while the nonfrontal composite parcels originate lower in the atmosphere where normal lapse rates resume (Figure 11(b)). The frontal composite also features a comparable most unstable convective inhibition (MUCIN) value to the nonfrontal composite, but the most unstable convective available potential energy (MUCAPE) is much smaller in the frontal composite (Figure 11(c)). We also note that the composite for the frontal case collection suggests a convective column, which, on average, should be more shallow than its nonfrontal counterpart, as the equilibrium level (EL) is much lower in the frontal composite (Figures 11(a) and 11(c)).

Finally, we look to wind differences between these two composites (Figure 11(c)). There is a stark difference in the lowest $\sim 100 \mathrm{mb}$, with a deeper, more consistent easterly flow below the inversion in the frontal case composite as opposed to the nonfrontal composite. Thus, both profiles exhibit veering signatures in the lowest $100 \mathrm{mb}$, suggesting warm advection; not surprisingly, this is more pronounced in the frontal composite. Above the inversion level, the profiles are 


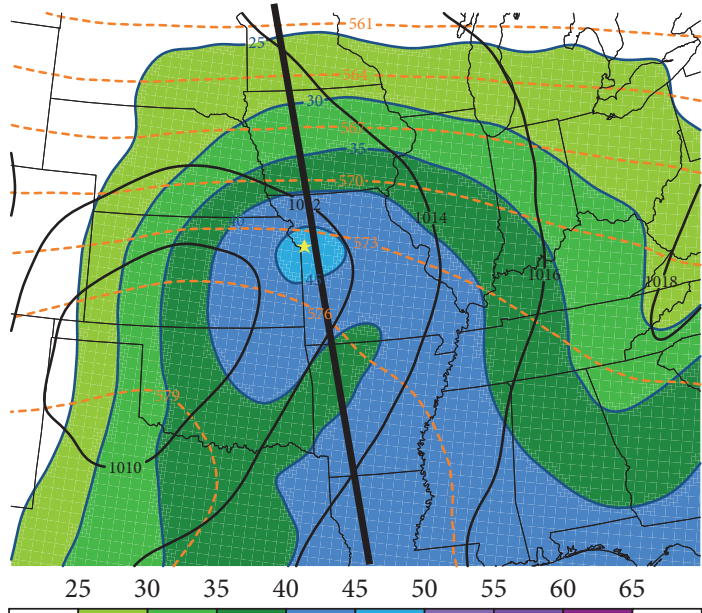

Elevated heavy rain composite 1000-500-hPa thickness [dkm, dashed], mean sea-level pressure [mb, solid black], and precipitable water [mm, shaded]

(a)

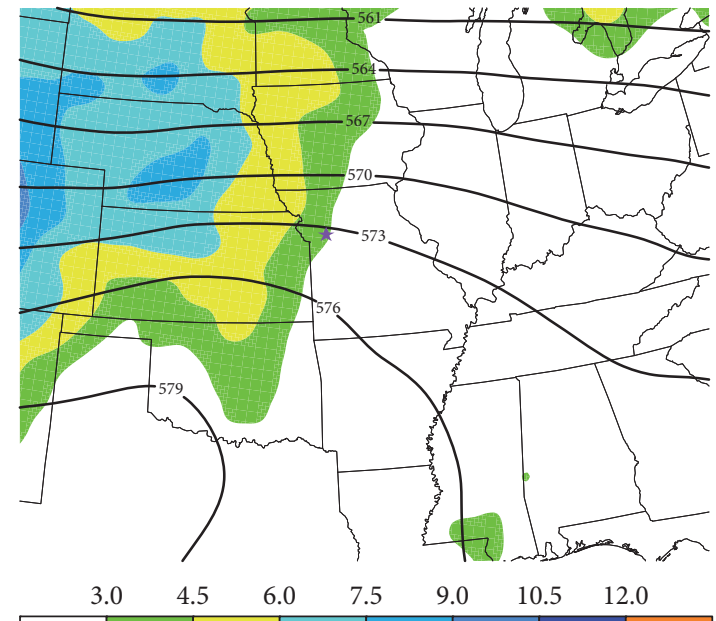

Composite mean 1000-500-hPa layer thickness [dkm, contours] and 75-25 percentile spread [dkm, color-filled] at $t=0$

(c)

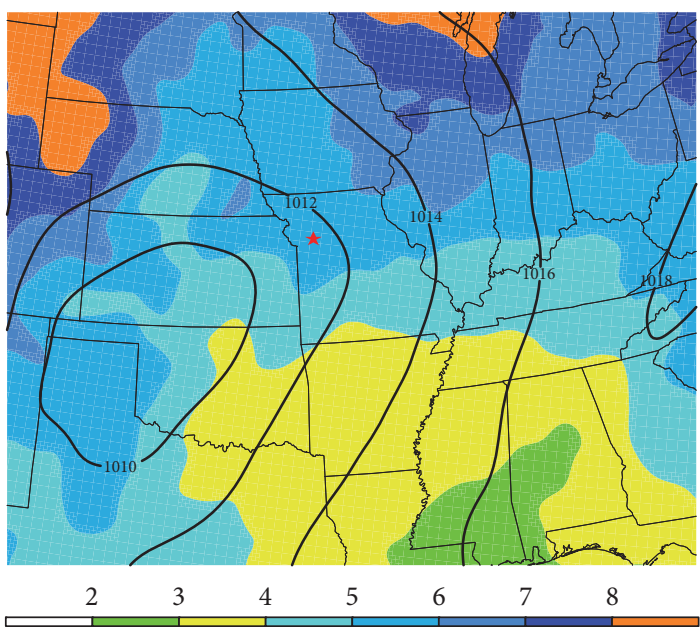

Composite mean sea-level pressure [hPa, contours] and 75-25 percentile spread [hPa, shaded] at $t=0$

(b)

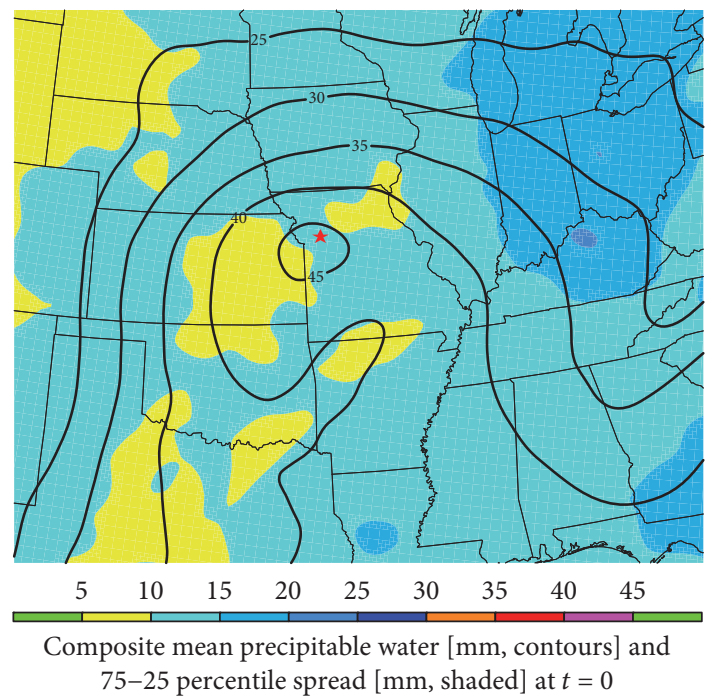

(d)

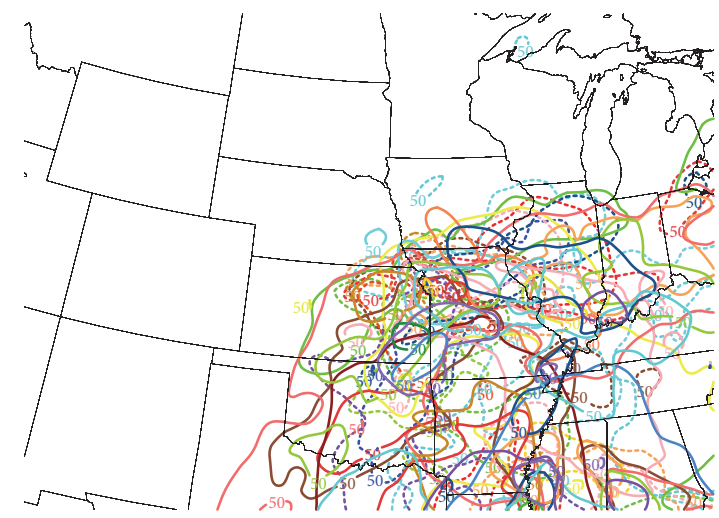

50-mm PWAT contours for each component case

(e)

FIgURE 9: EAX CWA composite for $0-3 \mathrm{hr}$ prior to event time showing (a) average mean sea level pressure (solid black, hPa), 1000-500 hPa layer thickness (dashed brown, $\mathrm{dkm}$ ), and precipitable water (color-filled, $\mathrm{mm}$ ); (b) average mean sea level pressure (black, hPa) and 75-25 percentile spread (color-filled, hPa); (c) mean thickness (black, dkm) and 75-25 percentile spread (color-filled, kts); (d) mean precipitable water (black, $\mathrm{mm}$ ) and 75-25 percentile spread (color-filled, in) (e) regional spaghetti plot of $50 \mathrm{~mm}$ of precipitable water from each composite member (each is a different color). The star is located at the centroid of the CWA. Heavy dark line in Figure 9(a) is the cross-section line in Figure 10. 


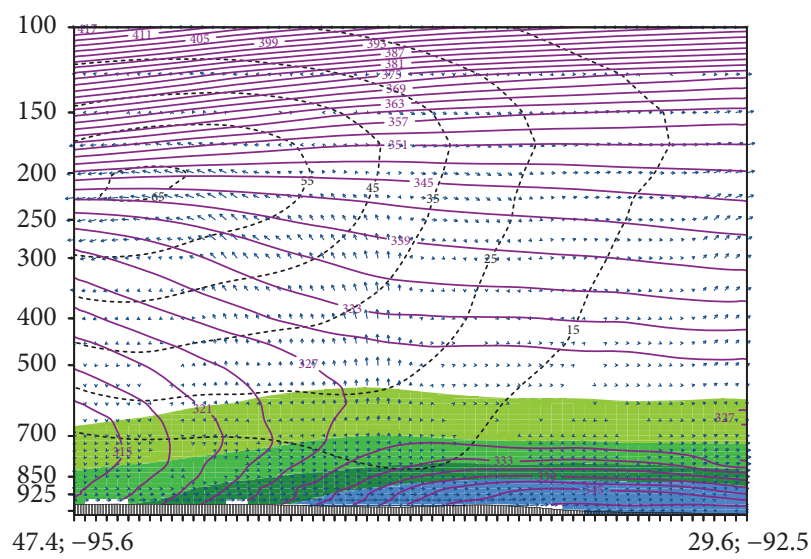

$\longrightarrow 20 . \mathrm{kts}$

6

9

18

Cross-section of Theta-E [K, solid], mixing ratio $[\mathrm{g} / \mathrm{kg}$, shaded], wind speed [kts, dashed], and ageostrophic circulation [kts, vectors] at $t=-12 \mathrm{~h}$

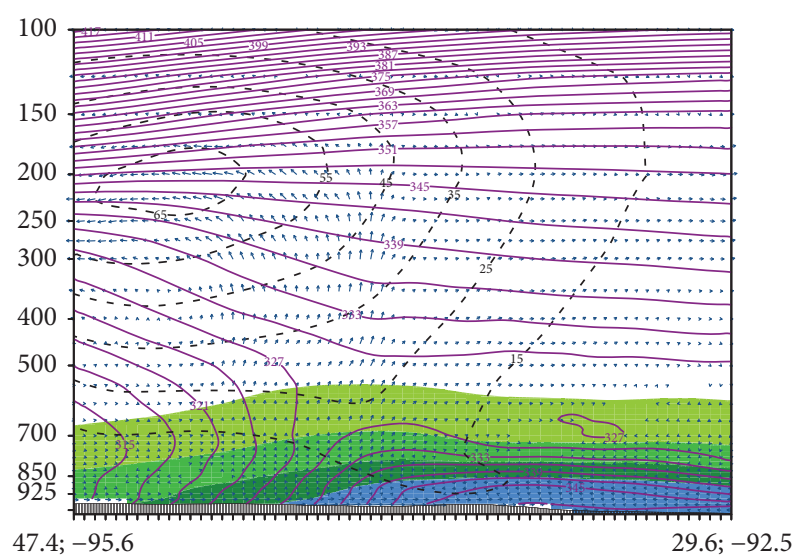

$\longrightarrow 20 . \mathrm{kts}$

Cross-section of Theta-E [K, solid], mixing ratio $[\mathrm{g} / \mathrm{kg}$, shaded], wind speed [kts, dashed], and ageostrophic circulation [kts, vectors] at $t=-6 \mathrm{~h}$

(a)

(b)

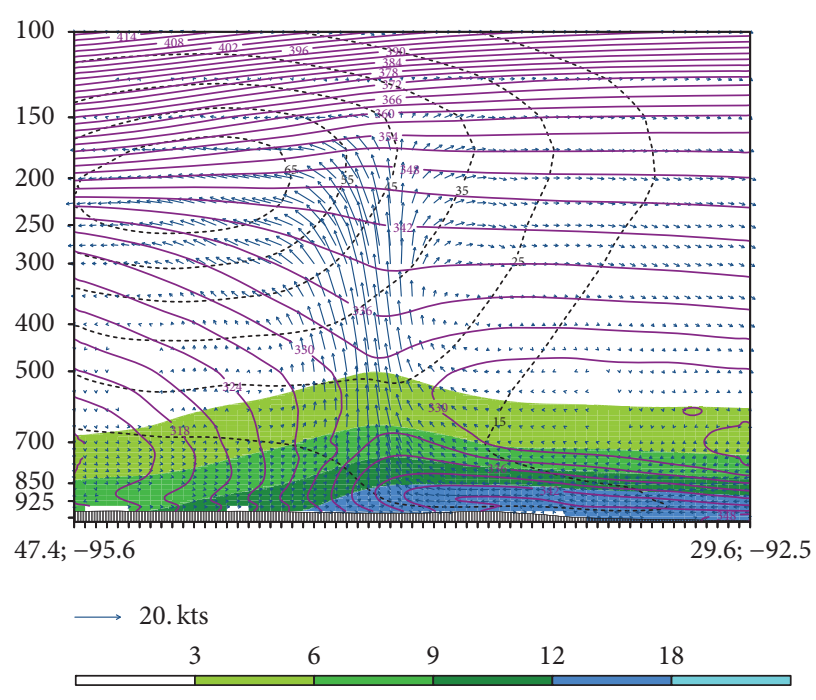

Cross-section of Theta-E [K, solid], mixing ratio [g/kg, shaded], wind speed [kts, dashed], and ageostrophic circulation [kts, vectors] at $t=0 \mathrm{~h}$

(c)

Figure 10: Composite cross-sections through the region as seen in Figure 9(a) at (a) 12 hours prior to the event; (b) 6 hours prior to the event; and (c) at the time of the event. Parameters shown are equivalent potential temperature (solid purple, K), scalar normal isotachs $\geq$ $60 \mathrm{kt}$ (dashed cyan), scaled ageostrophic circulation vectors, and mixing ratio (color-filled, $\mathrm{g} \mathrm{kg}^{-1}$ ).

strikingly similar. This view is corroborated by the nearly identical 0-6 km storm motion vectors of the frontal (from $270^{\circ}$ at 17 knots) and nonfrontal (from $275^{\circ}$ at 18 knots) case composites.

\section{Null Case}

With this work, we have used a large dataset of $>30$ years of elevated convection with heavy rainfall to corroborate the findings of previous investigators with our mean fields, along with adding a variability element to our analysis via the inclusion of the interquartile range on the mean plots. The mean fields also afforded the opportunity to seek out and examine an event that had many similar atmospheric fields and yet failed to produce significant precipitation. This was done via the analog engine at Saint Louis University.

4.1. Case Selection. Case selection was accomplished by submitting the aforementioned EAX composite fields (based upon dates between 1979 and 2010 during the months of April through September) to the SLU analog engine. Using standard variables at mandatory upper-air levels, the EAX 


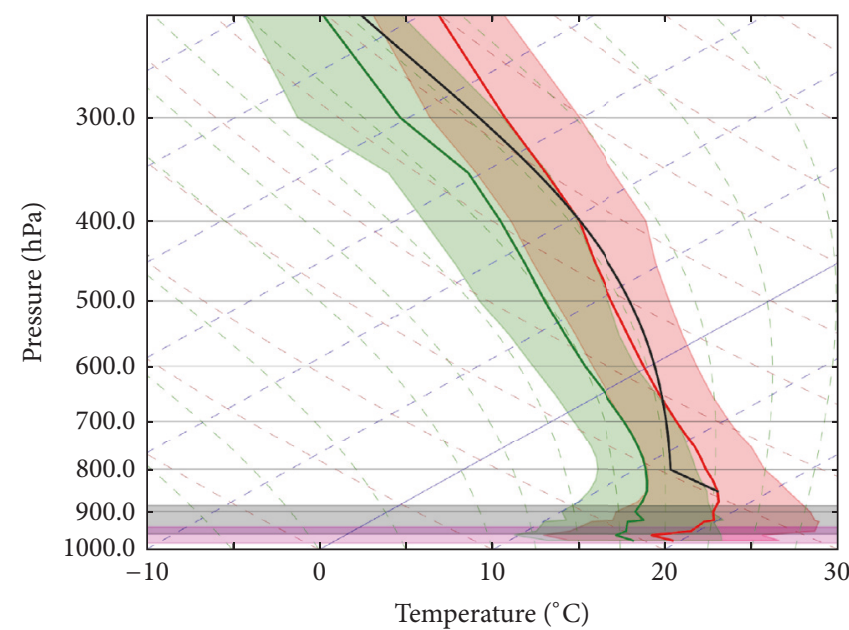

(a)

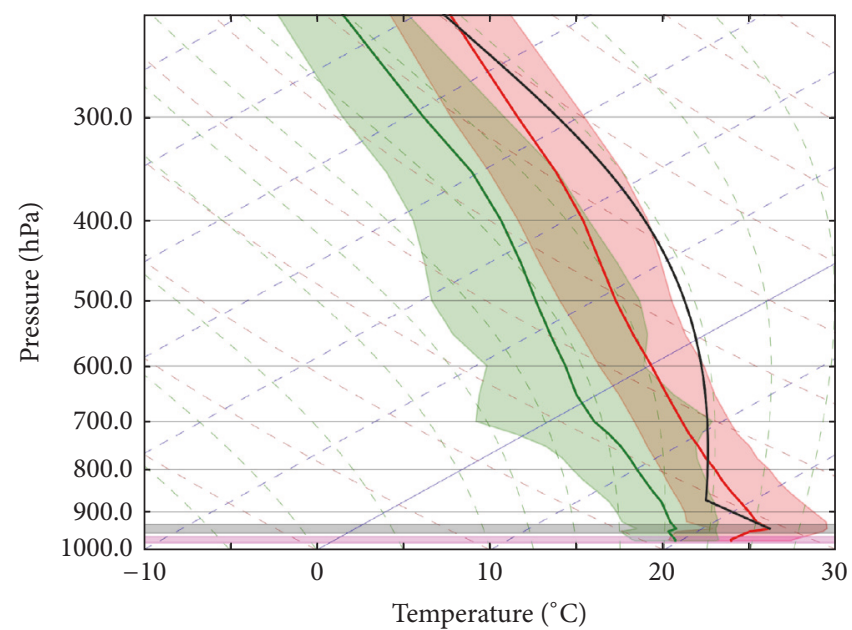

(b)
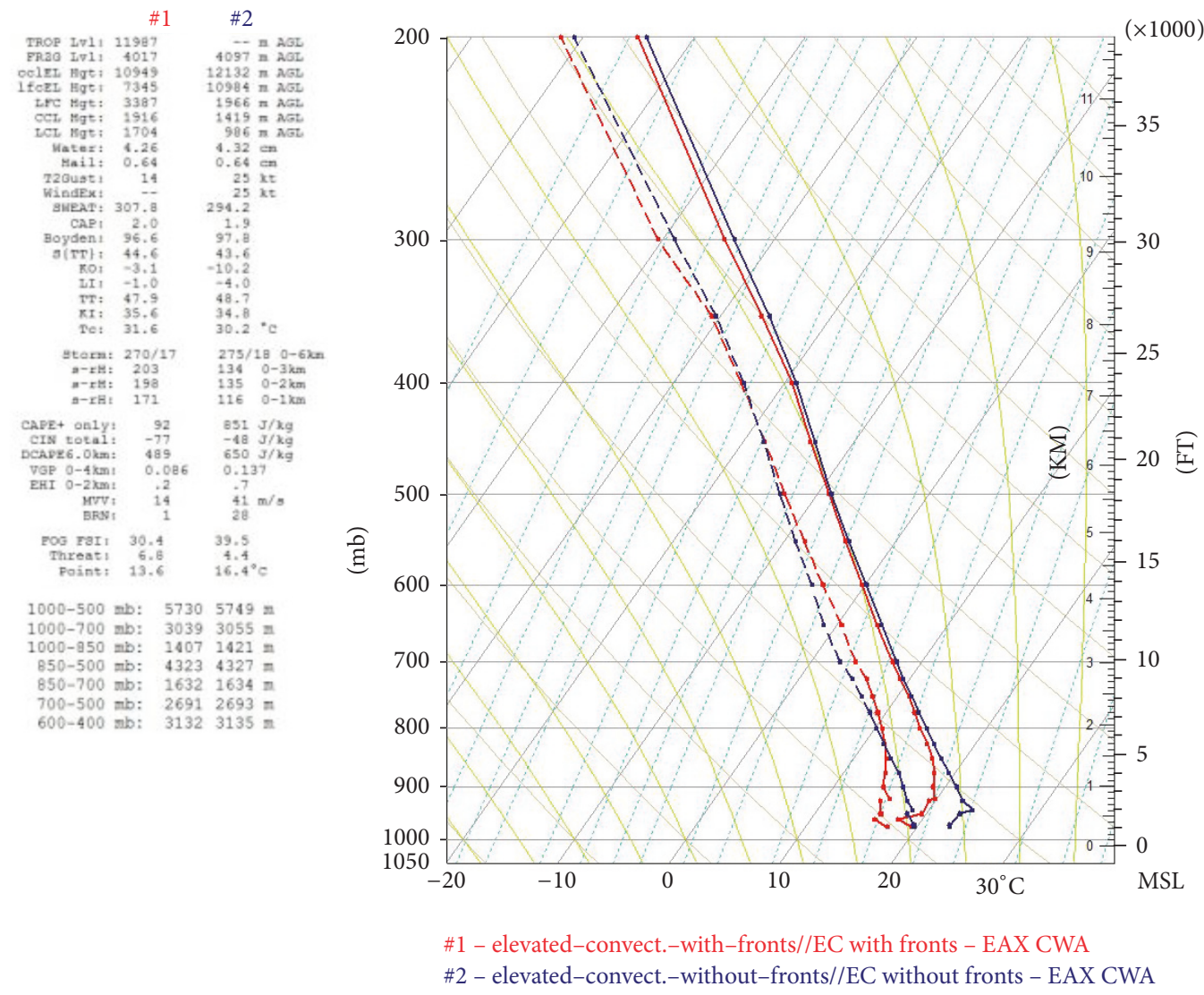

(c)

FIGURE 11: Composite soundings, with the bottom and top of the temperature inversion preserved, for (a) frontal and (b) nonfrontal case collections where the mean temperature (dew point) trace is solid red (green), with a red (green) envelope for the standard deviation of temperature (dew point), and (c) the same composite soundings, plotted together for frontal (red) and nonfrontal (blue) case collections with winds (plotted in knots on the right) for each.

composite patterns were matched for dozens of days. This matching process involves the computation of the spatial correlation and the mean absolute error over the region of interest for each parameter. These values are combined into a score which represents the spatial correlation that is reduced by the mean absolute error. These scores are aggregated into a single ranking to provide an estimate of the overall agreement between the composite and each day examined. This matching process involves a series of correlations and a minimizing of the root mean square error for each parameter 

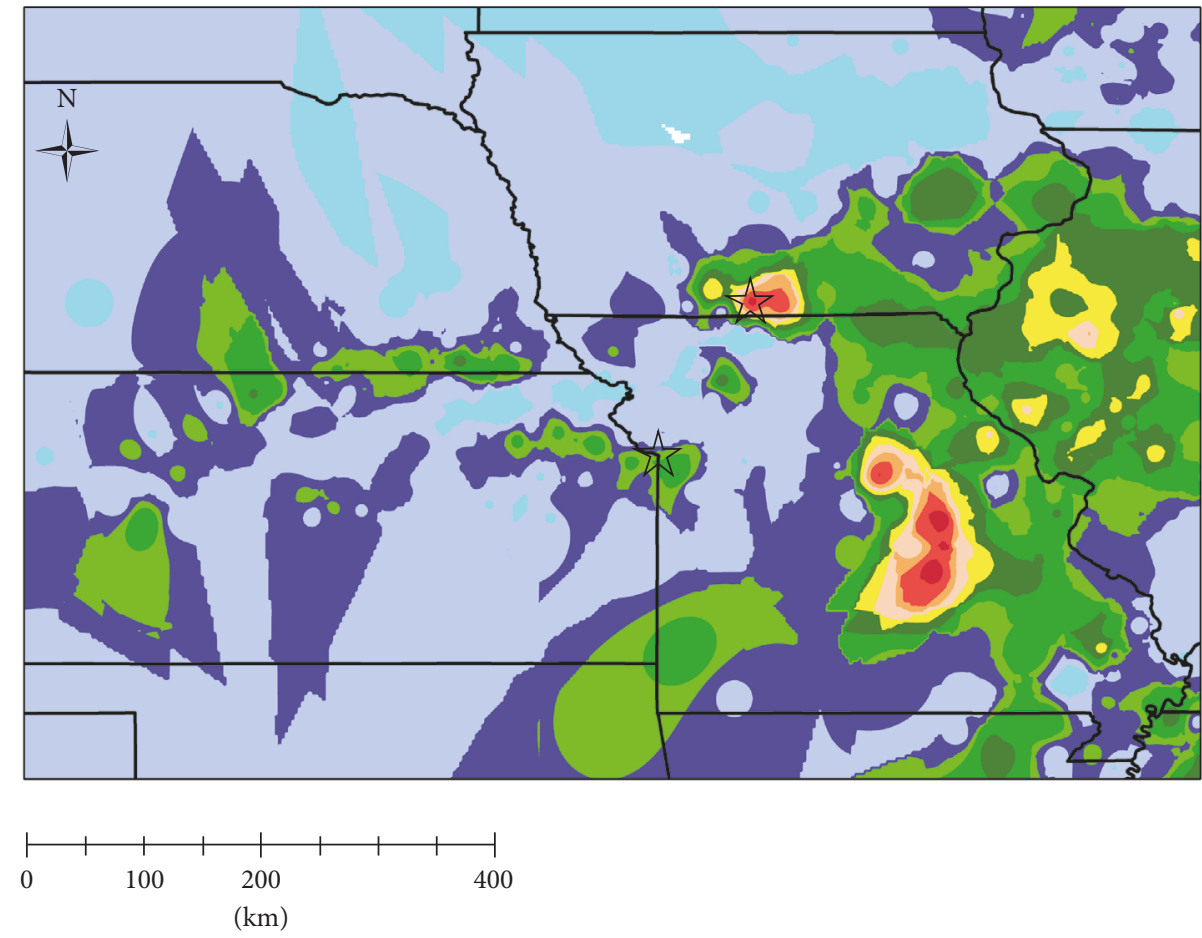

$1 \mathrm{~cm}=55 \mathrm{~km}$

\begin{tabular}{|c|c|c|c|c|c|c|c|c|c|c|c|}
\hline $\begin{array}{l}\text { m. } \\
\dot{v} \\
\text { ? }\end{array}$ & $\begin{array}{l}0 \\
\stackrel{1}{1} \\
\stackrel{2}{0} \\
0\end{array}$ & $\begin{array}{l}0 \\
0 \\
1 \\
1 \\
0 \\
0\end{array}$ & $\begin{array}{l}0 \\
0 \\
0 \\
1 \\
0 \\
\dot{1} \\
\text { in }\end{array}$ & $\begin{array}{l}0 \\
\text { in } \\
1 \\
0 \\
0 \\
0\end{array}$ & $\begin{array}{c}0 \\
\text { ஸे } \\
\text { 11 } \\
0 \\
0 \\
10\end{array}$ & $\begin{array}{l}0 \\
\text { 10 } \\
\text { गे } \\
1 \\
0 \\
\text { ஸे }\end{array}$ & $\begin{array}{l}0 \\
\text { 10 } \\
\text { † } \\
0 \\
0 \\
10 \\
m\end{array}$ & $\begin{array}{l}0 \\
\text { in } \\
10 \\
1 \\
0 \\
10 \\
\text { मे }\end{array}$ & $\begin{array}{l}0 \\
\text { in } \\
0 \\
1 \\
0 \\
\text { in } \\
\text { nn }\end{array}$ & 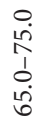 & $\begin{array}{l}0 \\
\text { in } \\
\infty \\
1 \\
0 \\
\text { in }\end{array}$ \\
\hline
\end{tabular}

FIgURE 12: 24-hour rainfall accumulation values (shaded, $\mathrm{mm}$ ) from the Advanced Hydrologic Prediction Service data set, for the period ending 1200 UTC 19 August 2002. Hollow black stars mark the locations of the soundings in Figure 17.

and level between the composite and the individual date. These values are then aggregated to form a single ranking of the matched individual dates from best to worst. From this list, events that were in the composite were removed immediately. The others were "false alarms," meaning that they did not exceed the criteria for the composite.

Not surprisingly, 17 of the top 20 matched dates featured some rainfall (but below the study threshold) in the EAX CWA, and 3 of the top matches were the very same dates that went into the making of the composite analyses. Yet, there was one date, ranked $4 \mathrm{th}$, in the analog matches that produced no significant widespread precipitation in the EAX CWA. This sample suggests a false alarm rate of 17 in every 20 instances $(85 \%)$ if one were to simply follow the composite with no other guidance.

4.2. 19 August 2002. 24-hour precipitation accumulations ending at 1200 UTC 19 August 2002 are shown in Figure 12. Very light precipitation amounts are shown across Kansas, Missouri, and Nebraska. A small swath of $>1.5$ inches $(38 \mathrm{~mm})$ of rain is depicted across a small area in southern Iowa, over the adjacent Des Moines CWA.
As before, we begin our analysis with the $250 \mathrm{hPa}$ jet (Figure 13) and we can see zonal flow across the EAX CWA. A $100+k t$ jet streak existed to the northeast over Wisconsin, with an elongated region of divergence in the streak's right entrance region and maximized over central Illinois. Even so, the interquartile range of the $250 \mathrm{hPa}$ divergence plot (Figure 4(d)) would still allow for the EAX CWA to be a viable candidate for heavy rainfall.

With $500 \mathrm{hPa}$ analysis being unrevealing in this case (not shown), the $850 \mathrm{hPa}$ analysis reveals broad southwesterly flow at that level, with a tiny $30 \mathrm{kt}$ jet core over southeast Kansas (Figure 14(a)). This placed the EAX CWA along the axis of the strongest flow, but the location in southern Iowa that experienced the rainfall would have fallen under the left exit region of the upper-level jet streak in question. Indeed the strongest $\theta_{e}$ advection at $850 \mathrm{hPa}$ (Figure 13(b)) extended from the location of the heaviest rain, eastward to central Illinois, beneath the level of the strongest $250 \mathrm{hPa}$ divergence.

This scenario is repeated in both the $K$ index field (Figure 15) as well as the precipitable water field (Figure 15). In both parameter plots, there are significant values over the EAX CWA, but the more pronounced signal existed further 


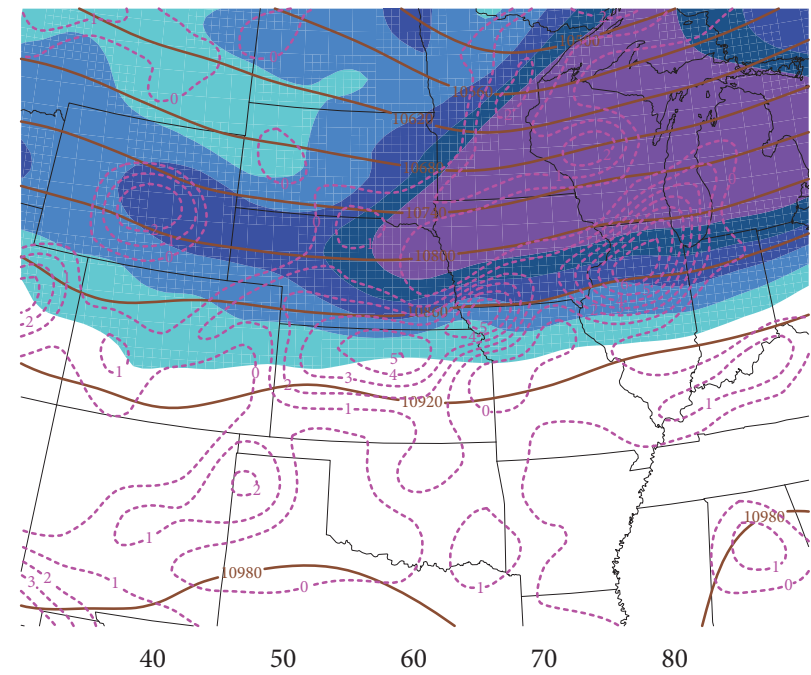

06Z 19 Aug 2002 case: 250-hPa heights (m), wind (kts), and divergence $\left[* 10^{-5} \mathrm{~s}^{-1}\right]$

FIGURE 13: As in Figure 4(a), but valid at 0600 UTC 19 August 2002.

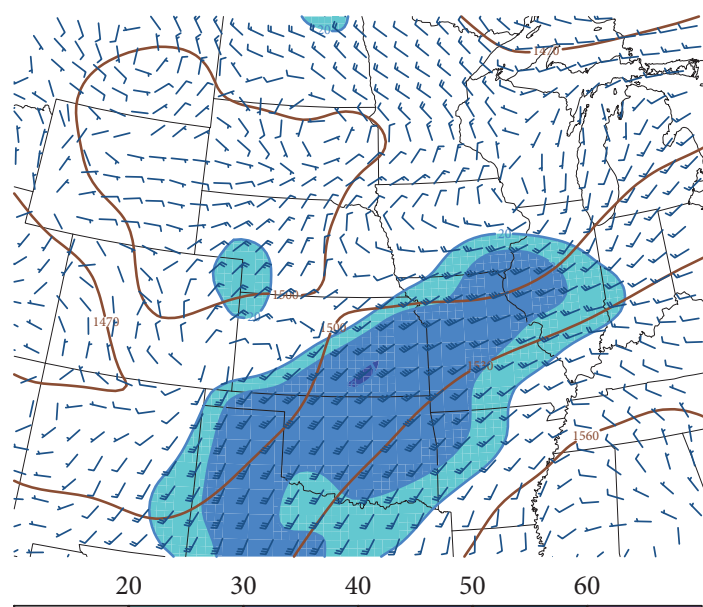

06Z 19 Aug 2002 case: 850-hPa height (m) and wind (kts)

(a)

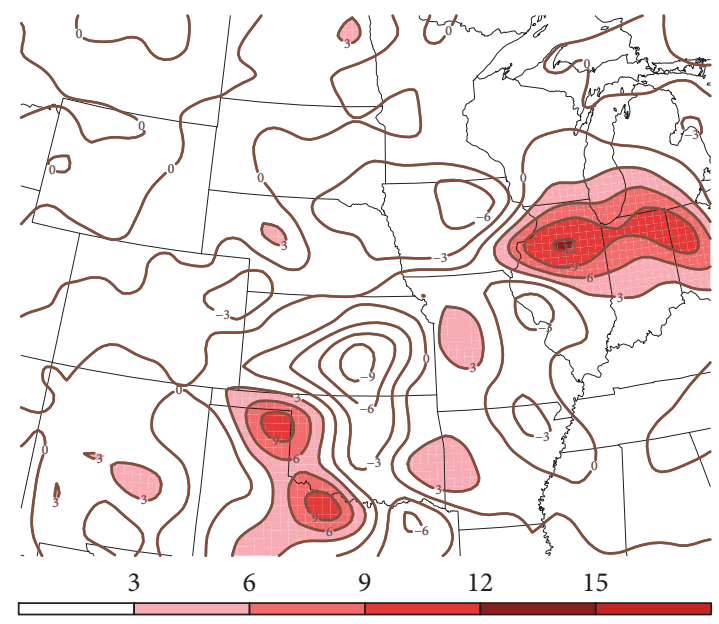

06Z 19 Aug 2002 case: 850-hPa Theta-e advection (K per $3 \mathrm{hr}$ )

(b)

FIgURE 14: Analysis valid at 0600 UTC 19 August 2002 of (a) $850 \mathrm{mb}$ geopotential height (solid black), isotachs $>20 \mathrm{kt}$ (shaded) and standard wind barbs; and (b) $850 \mathrm{mb} \theta_{e}$ advection [solid black; shaded $>+3 \mathrm{~K}\left(3 \mathrm{hr}^{-1}\right)$ ].

to the east over central Illinois. $K$ index values exceeded 40 , while the precipitable water values were over $50 \mathrm{~mm}(\sim 2 \mathrm{in}$.) over broader, more coincident area, further east.

Finally, the sea level pressure pattern (Figure 16(a)) revealed a broad trough of low pressure across northern Missouri and central Illinois. That same region was home to a region of 1000-500 hPa thickness diffluence (Figure 16(a)), supporting the idea of low-level convergence as suggested by [24] and the $850 \mathrm{hPa}$ analysis in Figure 14(a). Lastly, the $2 \mathrm{~m} \theta_{e}$ gradient across northern Missouri and along the Mississippi
River makes a strong case for this convection being elevated, and less so over the EAX CWA proper.

Soundings for both the EAX CWA (typified by the sounding from Kansas City [MKC] in Figure 17(a)) and the area of significant precipitation (Figure 17(b)) resemble the frontal (Figure 11(a)) and nonfrontal (Figure 11(b)) composites of elevated convection. It is clear from Figure 16 that the MKC sounding (Figure 17(a)) is on the warm side of the lowlevel thermal boundary, but the night time hour (0600 UTC) allowed a nonfrontal surface-based inversion to form. The 


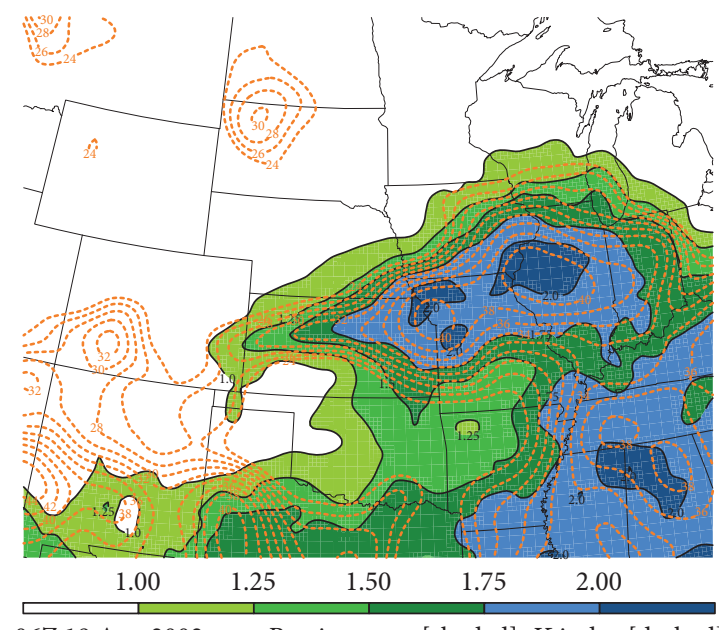

06Z 19 Aug 2002 case: Precip. water [shaded], $K$ index [dashed]

FIGURE 15: Analysis valid at 0600 UTC 19 August 2002 of precipitable water $>25 \mathrm{~mm}$ (solid black/shaded) and the $K$ index (dashed brown).

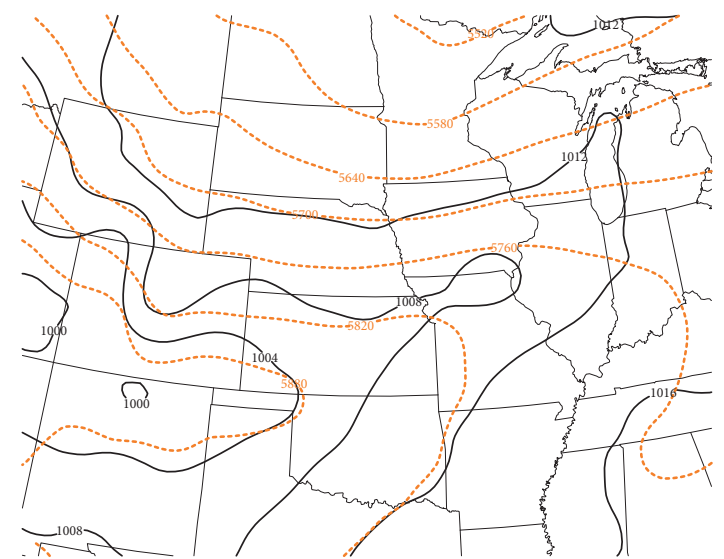

06Z 19 Aug 2002 case: Mean sea level pressure (mb), thickness (dkm)

(a)

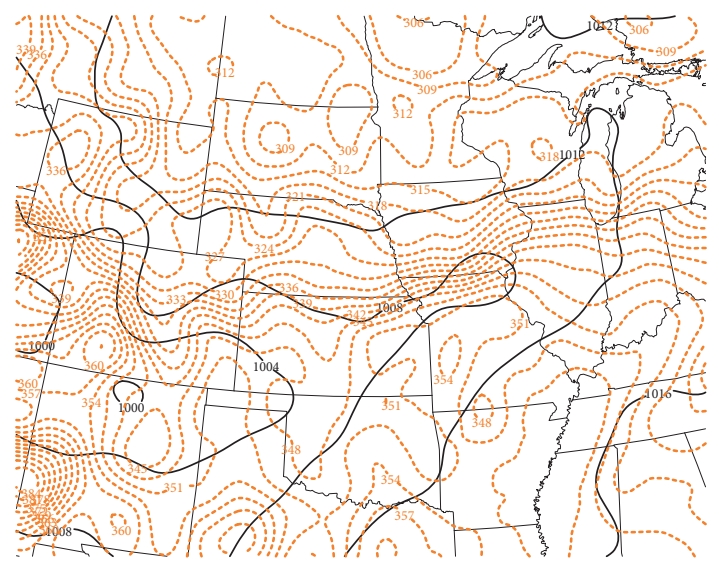

$06 Z 19$ Aug 2002 case: Mean sea level pressure $(\mathrm{mb})$, Theta-e $(\mathrm{K})$

(b)

Figure 16: Analysis valid at 0600 UTC 19 August 2002 of (a) mean sea level pressure (solid black; mb) and 1000-500 mb thickness (dashed brown; gpm) and (b) mean sea level pressure (solid black; mb) and $\theta_{e}$ (dashed brown; K).

lifting parcel level (LPL; $950 \mathrm{mb}$ ) in that area is lower, but the lapse rate in the free atmosphere helps to drive the MUCIN up to $90 \mathrm{~J} \mathrm{~kg}^{-1}$ and the level of free convection (LFC) to the $700 \mathrm{mb}$ level. Moreover, the vertical motion diagnosed by the NARR yielded downward motion at the LPL. Meanwhile, the heavy rainfall sounding from Lamoni, Iowa (Figure 17(b)), was clearly a frontal sounding, with easterly low-level flow, and a surface temperature cooler than the surface dew point in the MKC sounding (Figure 17(a)). The Lamoni sounding possessed a much higher LPL $(875 \mathrm{mb})$, but a much smaller CIN (19 $\left.\mathrm{J} \mathrm{kg}^{-1}\right)$, and lower LFC (760 mb). In addition the atmosphere over Lamoni, Iowa, is moister up to $\sim 700 \mathrm{mb}$, with NARR diagnosed upward motions of $-6 \mu \mathrm{b} \mathrm{s}^{-1}$ at the LPL (875 mb).

In summary, the EAX CWA seems a plausible location for heavy rainfall. Both upper-level divergence and low-level support (jet location and $\theta_{e}$ advection) are amenable but stronger to the east over Illinois. Moreover, the EAX CWA straddles the low-level thermal boundary, with the best $K$ Index values to the south over the warmer air. However, the sounding analyses reveal a more capped environment over the MKC area, further hampered by downward motion at the LPL. Thus the necessary ingredients for heavy rainfall with elevated convection are present over the entire area, but were maximized to the northeast over Iowa and Illinois and with sufficient lift to release the instability.

\section{Conclusions}

This study extends the results of [25] and provides a statistically meaningful look at elevated convection events with heavy rainfall in the favored Missouri-Kansas-Oklahoma 


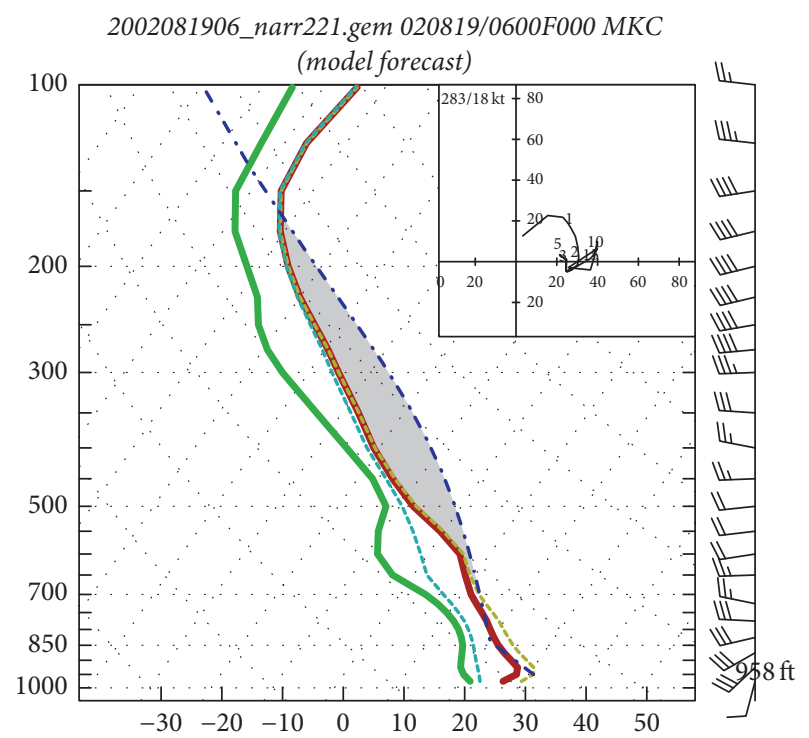

(a)

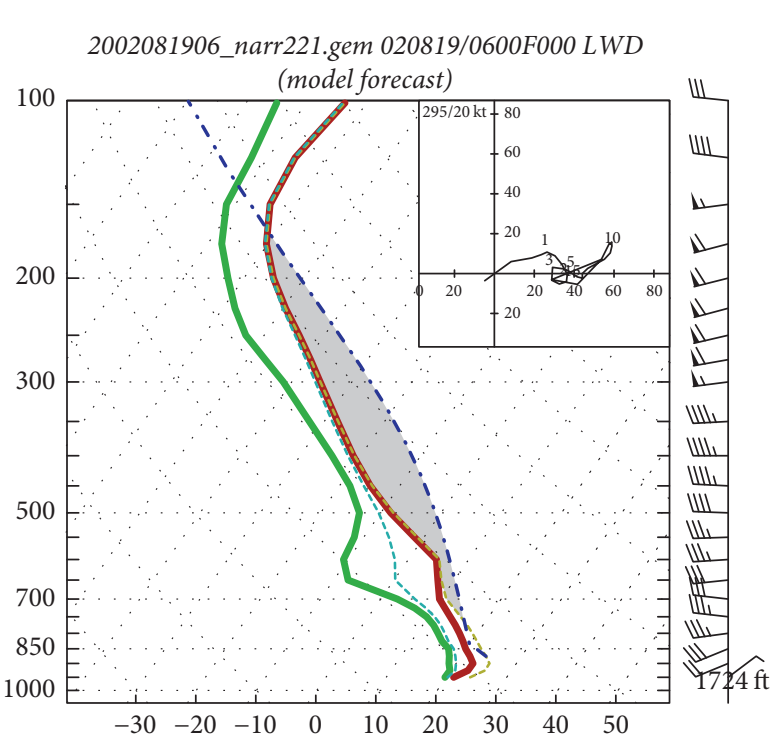

(b)

FIGURE 17: Sounding analyses for (a) Kansas City, Missouri (MKC) and (b) Lamoni, Iowa (LWD) from the NARR grid files, valid at 0600 UTC 19 August 2002. Analysis.

region. The present study does not focus strictly on the occurrence of flash flooding as did [7], but then neither did the work of Colman $[1,2]$. Instead our search was focused on elevated convection events that produced over $50 \mathrm{~mm}\left(2^{\prime \prime}\right)$ of rainfall in 24 hours. Even so, $68 \%$ of the events in this study had associated reports of flooding or flash flooding in the Storm Events Database or Storm Data Publications, and our search spanned time frames that dwarfed both the $[1,2]$ and [7] studies. Thus, our study provides not only robust mean fields, but also a measure of variability from a larger sample that allows greater confidence than evaluation of mean fields alone.

Of the many fields examined, several produced a significant signal in their mean fields, and a select few also generated surprisingly small IQR values. The fields with strong signal but also large variability were the $250 \mathrm{hPa}$ jet streak to the northeast of the region, with divergence values over the event site of $>3 \times 10^{-5} \mathrm{~s}^{-1}$. In addition, the event site was within or just south of $850 \mathrm{hPa} \theta_{e}$ advection maximum (and convergence maximum) allowing one to infer the low-level jet from the south-southwest. The fields with strong signal and small IQR were the $K$-index, with values $>32$, and precipitable water with values $>40 \mathrm{~mm}(\sim 1.6 \mathrm{in}$.), both of which were maximized very near to the event site. These parameters have been associated with the heavy rainfall environment for years [5]. The $2 \mathrm{~m} \theta_{e}$ gradient, which helps to confirm elevated convection, was well south of the event site, similar to $[1,7,12,13]$. Of course, the entire region is also typically found just upstream of the $500 \mathrm{hPa}$ ridge axis [5]. These features all point to a reliable signal of low-level warming and moistening above a frontal inversion, downstream of the exit region of a low-level jet streak and beneath upperlevel divergence [7]. Low-level increases in temperature and moisture are highlighted by the $850 \mathrm{mb}$ advection, as well as increases in potential instability revealed in the crosssection evolution. This parameter set highlights signatures of destabilization and forcing for ascent in a moistening atmosphere [5]. Soundings are critical to diagnose the type of elevated convection (frontal versus nonfrontal) and to aid in the assessment of whether the atmosphere, which plan-view composites suggest will produce elevated convection, will actually become convective. The typical arrangement of these plan-view parameters is shown in the schematic in Figure 18.

The results provided here largely corroborate those that have gone before regarding the typical environment for elevated convection with heavy rainfall as seen in planview $[5,7]$ and cross-section $[7,12]$. However, the current work also adds plan-view analysis of the variability within those fields via the interquartile range and those parameters which possess a strong signal but reduced variability, namely: the $200 \mathrm{hPa}$ divergence (a proxy for lift); the $K$ Index (a proxy for instability); and the precipitable water (a proxy for the column moisture). All of these parameters are highlighted in Figure 18. Additionally, both frontal and nonfrontal soundings from the elevated convection environment are a novel addition, and provide mean and standard deviation values. Both sounding types reveal a near-surface inversion, substantial CIN, and a need for organized forcing. This updated analysis will enhance the prediction of such heavy rainfall producing events.

\section{Disclosure}

Laurel P. McCoy current affiliation is NOAA/National Weather Service Office, Portland, Oregon. Any opinions, 


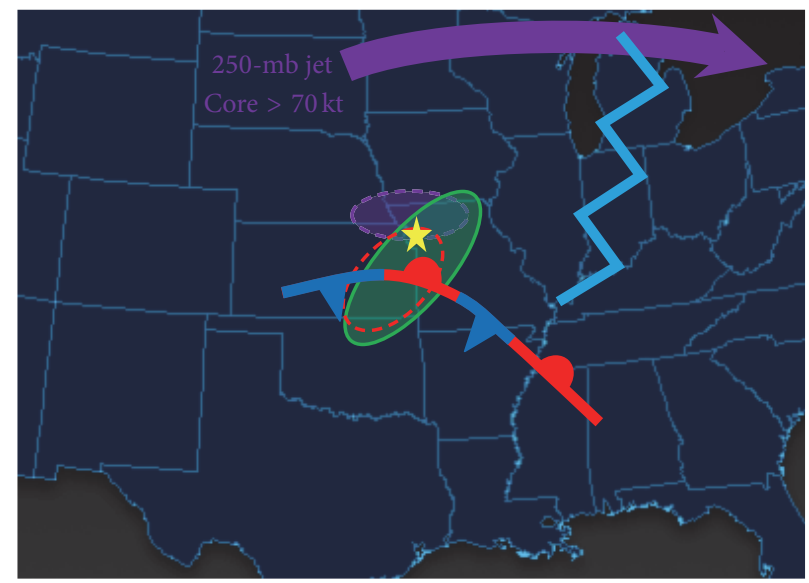

$$
\begin{aligned}
& \text { Moisture-PWATs }>1.6^{\prime \prime}(\sim 40 \mathrm{~mm}) \\
& \text { Lifting-250-mb DIV }>3 \times 10^{-5} \mathrm{~s}^{-1} \\
& \text { Instability-K index }>32
\end{aligned}
$$

FIGURE 18: Conceptual model of heavy rainfall events from elevated convection, based upon those parameters with larger mean signals and smaller interquartile ranges. The star marks the location where the heavy rainfall is anticipated; the jagged blue line represents the $500 \mathrm{hPa}$ ridge axis. Enhanced moisture is highlighted by the solid (green) oval, a proxy for lifting ( $250 \mathrm{hPa}$ divergence) is shown with the heavy dashed (purple) oval, and the instability (K Index) is shown with the fine dashed (red) oval.

findings, conclusions, or recommendations expressed herein are those of the authors and do not necessarily reflect the views of NSF.

\section{Conflicts of Interest}

The authors declare that there are no conflicts of interest regarding the publication of this paper.

\section{Acknowledgments}

The authors begin by thanking University of Missouri undergraduate students Katie Alexander and Marilyn Jones for their invaluable assistance with data reduction in the later stages of this research. This work is supported in part by the National Science Foundation (NSF), Award no. AGS1258358 .

\section{References}

[1] B. R. Colman, "Thunderstorms above frontal surfaces in environments without positive CAPE. Part I: a climatology," Monthly Weather Review, vol. 118, no. 5, pp. 1103-1121, 1990.

[2] B. R. Colman, "Thunderstorms above frontal surfaces in environments without positive CAPE. Part II: organization and instability mechanisms," Monthly Weather Review, vol. 118, no. 5, pp. 1123-1144, 1990.

[3] B. N. Grant, "Elevated cold-sector severe thunderstorms: a preliminary study," National Weather Digest, vol. 19, no. 4, pp. 25-31, 1995.

[4] S. M. Rochette and J. T. Moore, "Initiation of an elevated mesoscale convective system associated with heavy rainfall," Weather and Forecasting, vol. 11, no. 4, pp. 443-457, 1996.
[5] J. T. Moore, S. M. Rochette, F. H. Glass, and P. S. Market, "Elevated thunderstorms associated with heavy rainfall in the Midwest," in Preprints, 18th Conference on Severe Local Storms, pp. 772-776, American Meteorological Society, San Francisco, Calif, USA, 1996.

[6] S. M. Rochette, J. T. Moore, and P. S. Market, "The importance of parcel choice in elevated CAPE computations," National Weather Digest, vol. 23, no. 4, pp. 20-32, 1999.

[7] J. T. Moore, F. H. Glass, C. E. Graves, S. M. Rochette, and M. J. Singer, "The environment of warm-season elevated thunderstorms associated with heavy rainfall over the central United States," Weather and Forecasting, vol. 18, no. 5, pp. 861-878, 2003.

[8] S. F. Corfidi, S. J. Corfidi, and D. M. Schultz, "Elevated convection and castellanus: ambiguities, significance, and questions," Weather and Forecasting, vol. 23, no. 6, pp. 1280-1303, 2008.

[9] P. Markowski and Y. Richardson, Mesoscale Meteorology in Midlatitudes, John Wiley and Sons, New York, NY, USA, 2010.

[10] K. L. Horgan, D. M. Schultz, J. E. Hales Jr., S. F. Corfidi, and R. H. Johns, "A five-year climatology of elevated severe convective storms in the United States east of the Rocky Mountains," Weather and Forecasting, vol. 22, no. 5, pp. 1031-1044, 2007.

[11] R. H. Johns and C. A. Doswell, "Severe local storms forecasting," Weather and Forecasting, vol. 7, no. 4, pp. 588-612, 1992.

[12] S. B. Trier and D. B. Parsons, "Evolution of environmental conditions preceding the development of a nocturnal mesoscale convective complex," Monthly Weather Review, vol. 121, no. 4, pp. 1078-1098, 1993.

[13] J. A. Augustine and F. Caracena, "Lower-tropospheric precursors to nocturnal MCS development over the central United States," Weather \& Forecasting, vol. 9, no. 1, pp. 116-135, 1994.

[14] S. F. Corfidi, "Cold pools and MCS propagation: forecasting the motion of downwind-developing MCSs," Weather and Forecasting, vol. 18, no. 6, pp. 997-1017, 2003.

[15] R. L. Thompson, C. M. Mead, and R. Edwards, "Effective storm-relative helicity and bulk shear in supercell thunderstorm 
environments," Weather and Forecasting, vol. 22, no. 1, pp. 102115, 2007.

[16] M. D. Parker, "Response of simulated squall lines to low-level cooling," Journal of the Atmospheric Sciences, vol. 65, no. 4, pp. 1323-1341, 2008.

[17] R. S. Schumacher, "Sensitivity of precipitation accumulation in elevated convective systems to small changes in low-level moisture," Journal of the Atmospheric Sciences, vol. 72, no. 6, pp. 2507-2524, 2015.

[18] F. Mesinger, G. DiMego, E. Kalnay et al., "North American regional reanalysis," Bulletin of the American Meteorological Society, vol. 87, no. 3, pp. 343-360, 2006.

[19] J. P. Gosselin, C. M. Gravelle, C. E. Graves, J. P. Gagan, and F. H. Glass, "Composite analysis of heavy snow events within the Springfield and St. Louis, Missouri National Weather Service county warning areas," National Weather Digest, vol. 35, pp. 5781, 2011.

[20] R. A. Brown, "A compositing approach for preserving significant features in atmospheric profiles," Monthly Weather Review, vol. 121, no. 3, pp. 874-880, 1993.

[21] P. S. Market, A. M. Oravets, D. Gaede et al., "Proximity soundings of thundersnow in the central United States," Journal of Geophysical Research Atmospheres, vol. 111, no. 19, Article ID D19208, 2006.

[22] K. Ninomiya, "Mesoscale modification of synoptic situations from thunderstorm development as revealed by ATS III and aerological data," Journal of Applied Meteorology, vol. 10, no. 6, pp. 1103-1121, 1971.

[23] S. Miller, Applied Thermodynamics for Meteorologists, Cambridge University Press, 2015.

[24] T. W. Funk, "Forecasting techniques utilized by the Forecast Branch of the National Meteorological Center during a major convective rainfall event," Weather and Forecasting, vol. 6, no. 4, pp. 548-564, 1991.

[25] L. M. McCoy, Analysis of heavy-rain-producing elevated thunderstorms in the MO-KS-OK region of the United States [M.S. thesis], University of Missouri, 2014. 

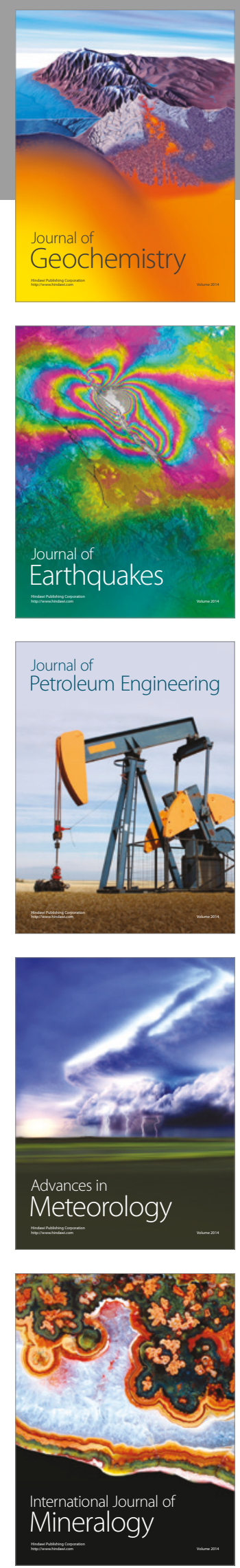
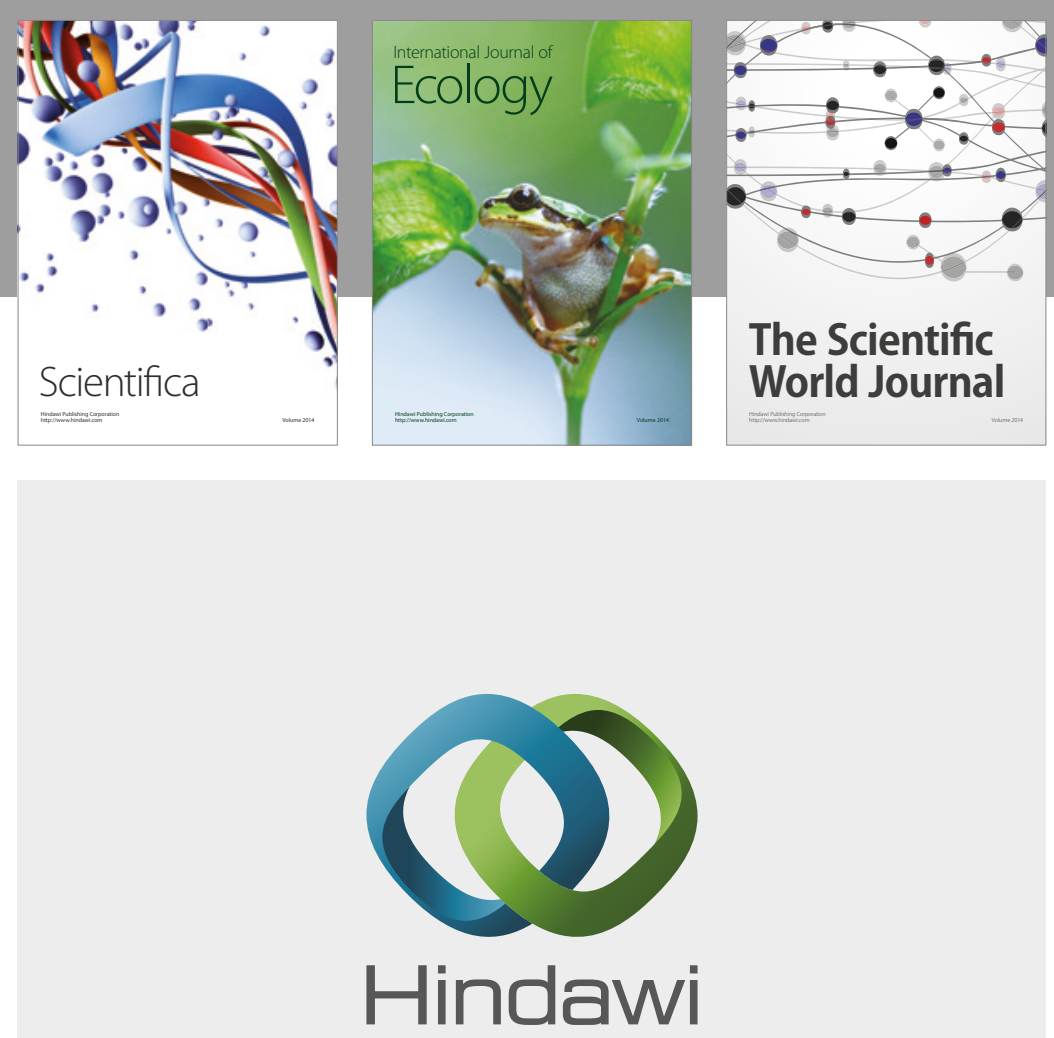

Submit your manuscripts at

https://www.hindawi.com
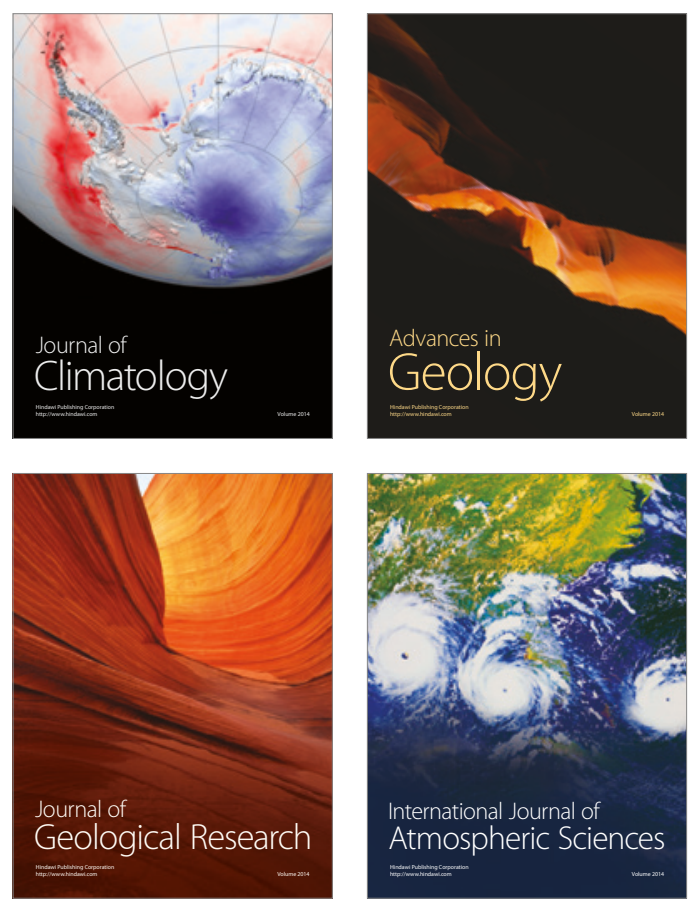

The Scientific

World Journal
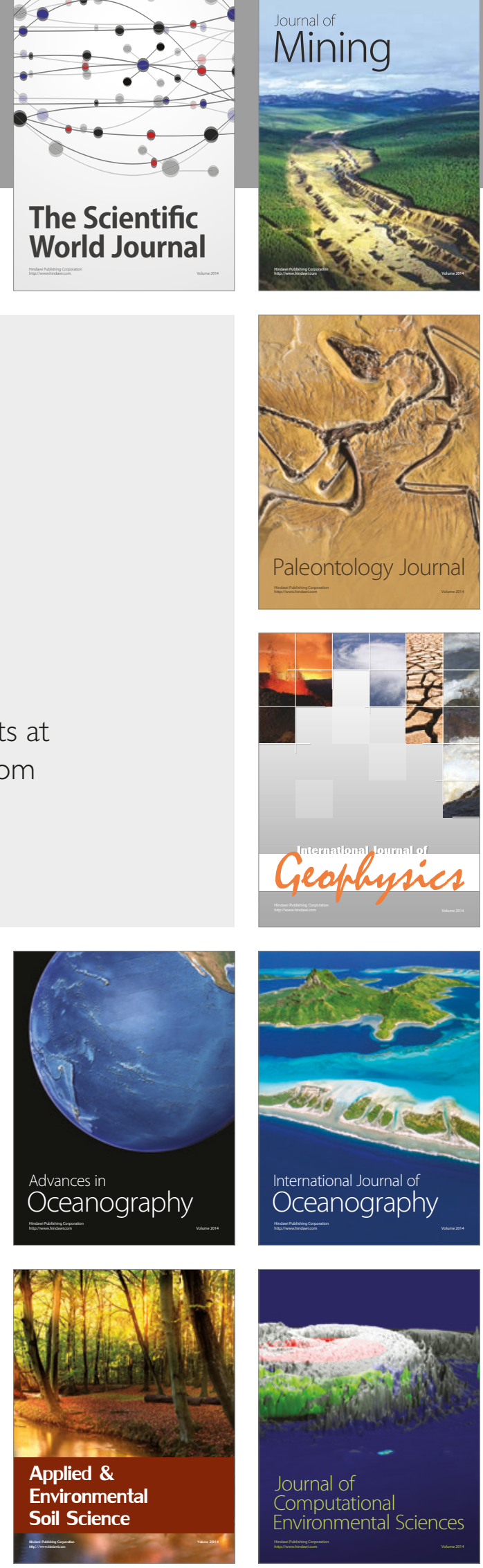